\title{
REMOVAL ORANGE G DYE FROM AQUEOUS SOLUTIONS USING GRAPHENE OXIDE/MAGNESIUM OXIDE NANO COMPOSITE
}

\author{
Amir. Fahdil. Dawood AL-Niaimi and Abdulilah. Ahmed Olaiwy
}

Department chemistry, College of Science, University Diyala, Iraq.

\begin{abstract}
Nanocomposite comprised of grapheme oxide (GO) nanosheets and magnesium oxide (MgO) nanoparticles were synthesized by a sol-gel method. The GO/MgONCs synthesized weight ratio of GO /MgO 1:1 The synthesized samples were characterized using (FT-IR,X-ray diffraction, AFM ,SEM) The results showed that Mg0 particles was decorated on GO. The adsorption of Orange $\mathrm{G}$ dye from aqueous solution onto $\mathrm{GO} / \mathrm{MgO} \mathrm{NCs}$ as adsorbent by batch method, under various experimental conditions including contact time, $\mathrm{GO} / \mathrm{MgO} \mathrm{NCs}$ dosage , $\mathrm{pH}$, temperature, and initial Orange G dye concentration was investigated. Adsorption isotherms been used to test the adsorption data for (Langmuir, Freundlich, Dubinin, Temkin) as it was fit to Langmuir isotherm and type $\mathrm{S}$ according to Gilles classification.Thermodynamic functions data such as $\left(\Delta \mathrm{H}^{\circ}, \Delta \mathrm{G}^{\circ}, \Delta \mathrm{S}^{\circ}\right)$ of the adsorption process were calculated, which show the adsorption endothermic process and the value of $\Delta G^{\circ}$ was negative this indicate that the adsorption happened spontaneously while the value of $\Delta \mathrm{S}^{\circ}$ is positive that meaning the movement of dye molecules is unrestricted. Kinetic data were fit to pseudo- second order mode.
\end{abstract}

Keywords: Adsorption, Orange G, GO/MgONCs, Thermodynamics and Kinetic study.

\section{INTRODUCTION}

Dyes are widely used in industries such as textile, leather; food and plastic materials ${ }^{1}$. The waste water generated from industrial activity contain a variety of potentially toxic and environmentally harmful compounds. These compound present an increasingly serious threat to human and environmental health ${ }^{2}$. The most dyes are stable to light and oxidizing agents in nature ${ }^{3}$. Various methods such as biodegradation $^{4}$ advanced oxidation ${ }^{5}$, ultrafiltration $^{6}$ and adsorption ${ }^{7}$ have been applied to remove dyes from aqueous solutions. Adsorption has gained increased attention in removing dyes because its simplicity, high efficiency, minimization of chemical sludge, and regeneration of adsorbents. A wide variety of adsorbents, have been used for the remove of dyes from aqueous solutions including activated carbon, zeolite $^{8}$ 'perlite ${ }^{9}$, chitin ${ }^{10}$ 'lemon peel ${ }^{11}$, graphene oxide $^{12}$. Graphene oxide (GO) is an oxidized derivative of graphene which contains epoxide ,hydroxyl and carboxyl groups ${ }^{13}$. These functions groups lead to the negative charge, hydrophilicity and easy dispersion of
GO in aqueous solutions ${ }^{14}$.These properties make GO a great candidate for removal of different pollutants by adsorption due its high surface area and functionalities. Magnesium oxide $(\mathrm{MgO})$ with a destructive sorbent, high surface reactivity, high adsorption capacity and ease of production. Recently. MgO nano particles have been used for the removal of dyes, catechol, phenol, fluoride, and formaldehyde from wastewater ${ }^{15,16}$.Thus ,considering the synergistic advantage and decoration of $\mathrm{MgO}$ NCs over GO platform, $\mathrm{GO} / \mathrm{MgO}$ nanocomposites can be considered as a potential adsorbent for removal of pollutants. Therefore, the aim of this is investigate the adsorption of orange $G$ dye from its aqueous solutions by GO/MgO NCs .

\section{MATERIALS AND EXPERIMENTAL}

UV-Visible (Shimadzu, Japan 1700) was used to measure the dye concentration in aqueous solution. The $\mathrm{pH}$ of all solutions was recorded by $\mathrm{pH}$ meter (7110 (wtw), Germany).The temperature was controlled using isothermal water bath shaker (BS-11, Korea). ZnO characterized using XRD (Shimadzu company 
(Japan) (XRD-6000)) with Cu ka radiation $(\lambda=$ $0.15406 \mathrm{~nm}$ ), the measurements conditions of XRD are $40 \mathrm{kv}, 30 \mathrm{~mA}$, the scanning range is $10-120^{\circ}$ and the scanning speed $5 \mathrm{deg} / \mathrm{min}$. ,FTIR(Shimadzu (IR PRESTIGE 21) with $\mathrm{KBr}$ pellet technique. The effective range was from 4000 to $400 \mathrm{~cm}^{-1}$, AFM (SPM-AA3000, Advanced Angstrom Inc.), SEM (Type Tescan Brno-Mira 3LMU). All of the chemicals were used without further purification.

\section{Synthesis of GO}

The GO is prepared according to the modified Hummers method ${ }^{17}$, Briefly ,2g of graphite powder was mixed with $50 \mathrm{ml}$ sulfuric acid (98wt\%) and $2 \mathrm{~g}$ sodium nitrate in a $500 \mathrm{~mL}$ flask in an ice bath at $0^{\circ} \mathrm{C}$. While vigorously stirring, $6 \mathrm{~g}$ of potassium permanganate was gradually added to the flask, and stirring was maintained for $2 \mathrm{~h}$ where after $100 \mathrm{Ml}$ of $\mathrm{DI}$ water was added to the solution .The solution temperature was rapidly increased to $98^{\circ} \mathrm{C}$ and maintained for $30 \mathrm{~min}$. Then $100 \mathrm{~mL}$ DI water was added and the temperature was increased rapidly to $98^{\circ} \mathrm{C}$ and kept for 30 min.300 mL DI water was then added to the flask. Following that, $20 \mathrm{~mL}$ hydrogen peroxide (30wt\%) solution was added, causing the color of the mixture turn to yellow. The mixture was filtered and washed with hydrochloric acid $(5 \%)$ solution and DI water several times to eliminate any residuals .Ultimately, GO was synthesized by sonication of the dispersion for 60 min and drying at $60^{\circ} \mathrm{C}$.

\section{Synthesis of MgO NPs}

$\mathrm{MgO}$ nanoparticles were prepared as follow,2 $\mathrm{g}$ of magnesium chloride hexahydrate was dissolved in $25 \mathrm{~mL}$ of DI water in $250 \mathrm{~mL}$ flask ,and $2.06 \mathrm{~g}$ of citric acid was dissolved in 25 $\mathrm{mL}$ of $\mathrm{DI}$ water in $250 \mathrm{~mL}$ flask. Then mixing by addition solution $\mathrm{MgCl}_{2} \cdot 6 \mathrm{H}_{2} \mathrm{O}$ to the solution citric acid by slowly with string ,then added some drops of ammonia slowly for to be $\mathrm{pH} 7$. And increase temperature to $60^{\circ} \mathrm{C}$ with string for $1 \mathrm{~h}$ to generate the magnesium hydroxide. The solution was then centrifuged to separate the $\mathrm{Mg}(\mathrm{OH})_{2}$ gel from the suspension. $\mathrm{Mg}(\mathrm{OH})_{2}$ gel was washed a few times with DI

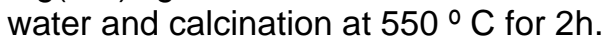

\section{Synthesis of GO/MgO NCs}

The ratio of GO/MgO NCs (1:1) were prepared by impregnation. Briefly, $1 \mathrm{~g}$ of $\mathrm{GO}$ was added in a baker with $1 \mathrm{~L} \mathrm{DI}$ water and sonicated for $60 \mathrm{~min} .1 \mathrm{~g}$ of $\mathrm{MgO}$ nanoparticles were added to the dispersion baker .After $30 \mathrm{~min}$ of sonication, suspension was collected by centrifuging and dried at $60^{\circ} \mathrm{C}$.

\section{Synthesis of Orange G solution}

Orange $G$ is water soluble $(\lambda \max 478 \mathrm{~nm})$.A standard solution $(1000 \mathrm{mg} / \mathrm{L})$ was prepared by dissolving $1 \mathrm{~g}$ of Orange $\mathrm{G}$ dye in $1 \mathrm{~L}$ of $\mathrm{D} 1$ water .The experimental solution were prepared by diluting the standard solution of dye with $\mathrm{DI}$ water to give the appropriate concentration of the desired solutions (5 -30) $\mathrm{ppm}$ and the solutions are left for 24 hours in order to homogenize. Dilute $(0.1 \mathrm{M}) \mathrm{HCl}$ and $(0.1 \mathrm{M}) \mathrm{NaOH}$ was used for $\mathrm{pH}$ adjustment. The UV-Visible spectrometer used to determination calibration curve for Orange $G$ dye at $\lambda_{\max }(478 \mathrm{~nm})$. The dye adsorption by batch process to study different parameter such as contact time (25-125) min , dose of adsorbate (GO/MgO NCs ) (0.01-0.05g), pH (3-10), concentration of dye (5-30) ppm temperature $\left(20-40^{\circ} \mathrm{C}\right)$. The samples were shaken and kept in a thermostat for (125min) ,the samples were then filtered in a centrifuge for $15 \mathrm{~min}$ (at $3500 \mathrm{rpm}$ ) and then filtered again and analyzed spectrophotometric ally. The percentage dye adsorption from the aqueous solution was determined according to the following equation (\% Adsorption) ${ }^{18}$ :

$$
\% \text { Adsorption }=\frac{C_{o}-C_{e}}{C_{o}} \times 100
$$

Where $C_{\circ}$ and $C_{e}$ (both $m g / L$ ), are the initial concentration and the concentration at any time respectively. The adsorption capacity $Q_{e}$ (mg/g).

$$
Q_{e}=\frac{C_{o}-C_{e}}{m} \cdot V_{\text {sol. }}
$$

$Q_{\mathrm{e}}$ : Amount of solute adsorbed per unit weight of adsorbent $(\mathrm{mg} / \mathrm{g})$.

$\mathrm{C}_{\mathrm{e}}$ : Equilibrium concentration of solute $(\mathrm{mg} / \mathrm{L})$. $\mathrm{V}_{\text {sol. }}$ : Volume of solution (L).m: mass of adsorbent $(\mathrm{g})$.

\section{RESULTS AND DISCUSSION Characterization of GO, MgO and GO/ MgO NCs}

In order to investigate the functional groups of $\mathrm{MgO}$, GO, and GO/MgONCs ,FT-IR spectroscopy was used in the wave number range of $4000-400 \mathrm{~cm}^{-1}$ and the results shown in Figures 1-3. The FTIR spectra of $\mathrm{MgO}$ nanoparticles are shown in Figure (1). Metal oxides generally give absorption bands in fingerprint region i.e. below $1000 \mathrm{~cm}^{-1}$ arising from inter-atomic vibrations. The peak at 1632 $\mathrm{cm}^{-1}$ is correspond to $\mathrm{Mg}-\mathrm{O}$ stretching .The sharp peak observed at $3700 \mathrm{~cm}^{-1}$ on $\mathrm{MgO}$ and $\mathrm{GO} / \mathrm{MgONCs}$ is related to the presence of hydroxyl groups. For MgO NPs ,the hydroxyl group comes from the reaction between the surface of MgO NPs with water vapor in air or 
defects 16,19 .The intensity of this peak decrease in GO/MgONCs . Fig.2.Shows the infrared spectra of $\mathrm{GO}$ the band in the range of $3100-3500 \mathrm{~cm}^{-1}$ is assigned to the appearance of the stretching of $-\mathrm{OH}$ also for $\mathrm{GO} / \mathrm{MgONCs}^{20}$. The FTIR of $\mathrm{GO}$ is in a good agreement with other reported studies 21${ }^{23}$. The peaks at $1723 \mathrm{~cm}^{-1}$ and $1592 \mathrm{~cm}^{-1}$ correspond to $\mathrm{C}=\mathrm{O}$ and $\mathrm{C}=\mathrm{C}$ stretching . The band located at $1391 \mathrm{~cm}^{-1}$ and $1072 \mathrm{~cm}^{-1}$ are assigned to $\mathrm{C}-\mathrm{OH}$ stretching and $\mathrm{C}-\mathrm{O}-\mathrm{C}$ stretching vibrations mode of $\mathrm{sp}^{2}$ carbon skeletal ,respectively ${ }^{16}$. The FTIR for $\mathrm{GO} / \mathrm{MgONCs}$ is in a good agreement with ${ }^{16}$ the peak at $3364 \mathrm{~cm}^{-1}$ is related to the stretching of $-\mathrm{OH}$, the peak at $1446 \mathrm{~cm}^{-1}$ and $1087 \mathrm{~cm}^{-1}$ are assigned to $\mathrm{C}-\mathrm{OH}$ stretching and C- O - C stretching, respectively as show in Fig 3 .

Figure (4) shows diffraction peaks around the $2 \theta$ angles of $36.94^{\circ}(111), 42.92^{\circ}(200), 62.30^{\circ}$ (220), $74.69^{\circ}(311)$ and $78.63^{\circ}(222)$ belong to cubic structure ..All diffraction data are in good agreement with JCPDS files No., , and the diffraction peaks are sharp and the crystal grows completely with high purity and good agreement with ref(16).In addition, the diffraction peaks at the $2 \theta$ value of $18.4^{\circ}, 32.8^{\circ}, 38.0^{\circ}, 50.90^{\circ} 58.7^{\circ}, 68.4^{\circ}$ and $72.1^{\circ}$ are matched with $\mathrm{Mg}(\mathrm{OH})_{2}$ was produced during modification of $\mathrm{GO}$ by $\mathrm{MgO}$ through a sonication process in DI water. Particle size for $\mathrm{MgO}$ has been estimated by using DebyeScherer's Equation

$$
D=0.9 \lambda / \beta \cos \theta
$$

Where $D$ : crystallite size,: $\lambda$ wave length $(0.154 \mathrm{~nm}),: \beta$ full width at half maximum,: $\theta$ diffraction angle, $\mathrm{D}=38.4 \mathrm{~nm}$ calcination at $550^{\circ} \mathrm{C}$ for $2 \mathrm{~h}$.

XRD patterns of $\mathrm{GO}$ and $\mathrm{GO} / \mathrm{MgO}$ are shown in figures $(5,6)$. As shown in Fig. 5, for the GO ,there is a strong and sharp peak located around $2 \theta=11.84^{\circ}$, corresponding to an interlayer distance of $(0.747 \mathrm{~nm})$, indicating the presence of oxygen functional groups on the surface of $\mathrm{GO}[16,24-26]$, also anther strong peak at $2 \theta=26$,corresponding to an interlayer distance of $(0.342 \mathrm{~nm})$, which indicated to carbon skeletal for nanosheet i.e graphite ${ }^{16}$. For $\mathrm{GO} / \mathrm{MgO} \mathrm{NCs}$ the peaks for $\mathrm{GO}, \mathrm{MgO}$ and $\mathrm{Mg}(\mathrm{OH})_{2}$ is also observed as shown in Fig .6., the peaks at $2 \theta=38.07^{\circ}(111)$ ,42.93(200) and 62.31ำ (220) belong to $\mathrm{MgO}$ .The diffraction peaks for $\mathrm{GO}$ at $2 \theta=11.33^{\circ}$ (001) and $26.82^{\circ}(002)$ is also observed and its intensity was decreased.
Atomic force microscopy (AFM) is a powerful characterization tool for determination the particle size and surface organization of the synthesized materials. The wet ability of a surface is dependent on its chemical composition, and also on the topography of the surfaces $\mathrm{MgO}, \mathrm{GO}$ and $\mathrm{GO} / \mathrm{MgO}$ are characterized by AFM images in two and three-dimensional and particles sizes distributions for adsorbent surface was represented in Figures (7-9). The average diameter of the particle was $(69.02 \mathrm{~nm})$ for $\mathrm{MgO}, 50 \%$ with average diameter $65 \mathrm{~nm}$, and $90 \%$ with average diameter $75 \mathrm{~nm}$, and the residual with diameter about $60-100 \mathrm{~nm}$,the highest for the sample under teats is $2.77 \mathrm{~nm}$ as shown in Fig .8.

AFM images show a three -dimensional AFM topography of $\mathrm{GO}$ as shown in fig.9. The highest value for thickness sheet is $6.21 \mathrm{~nm}$ ,the length sheet is $1455 \mathrm{~nm}$ and the high is 2.38nm.

AFM images show a three -dimensional AFM topography of $\mathrm{GO} / \mathrm{MgO} \mathrm{NCs}$ as shown in fig.10, show growth MgO Nanoparticles were sparsely distribution on surface of $\mathrm{GO}$, the high of sample $4.3 \mathrm{~nm}$. From Fig .10, observed the length sheet for GO (1499 nm) thickness sheet is $1.48 \mathrm{~nm}$.While the area of $\mathrm{MgO}$ molecular about $40.8 \mathrm{~nm}$, its length 85 $\mathrm{nm}$, while its width $0.48 \mathrm{~nm}$ as show on Fig .10.c The SEM images with different magnification power of $\mathrm{MgO}, \mathrm{GO}$ and $\mathrm{GO} / \mathrm{MgO} \mathrm{NCs}$ are shown in Figures (11-13) shows that $\mathrm{MgO}$ powders and porous and agglomerated consistent with previous studies 15,16,27. GO obtained from modified Hummers method is shown in Fig .12 , with a layer of wrinkled graphene oxide sheet at a low magnification. SEM images of $\mathrm{GO} / \mathrm{MgONCs}$ that are synthesized by the sonication method are shown in Fig 13.depicting that the surfaces of $\mathrm{GO}$ are covered by $\mathrm{MgO}$.It is evident from the SEM images that $\mathrm{MgO}$ particles were anchored heterogeneously on the GO sheets. GO sheets show agglomerated leaf -like structure $^{16}$.

\section{Determination of Equilibrium Time of adsorption}

Several adsorption experiments in (25-125) min of contact time range were performed and the results were shown in Fig.14. The removal rate of dye onto GO/MgO NCs gradually increased with the increase of contact time from 25 to $125 \mathrm{~min}$ and then remained constant ${ }^{28}$ with further increase in contact time; therefore, a period of $125 \mathrm{~min}$ of equilibrium was selected for the next studies. In the initial stage, dye contact quickly with a 
lot of available active sites on the surface of $\mathrm{GO} / \mathrm{MgO} \mathrm{NCs}$, resulting in the occurrence of the fast adsorption with increase of the contact time, the available active sites gradually lessened and the driving force weakened, leading to the slow adsorption process and taking long time to achieve adsorption equilibrium.

\section{Effect of pH}

The initial $\mathrm{pH}$ of the Orange $\mathrm{G}$ dye solution can significantly affect the adsorption capacity of the dye because it affects the charge distribution of the surface of the adsorbent (GO/MgO NCs) as well as adsorbate (the dye molecules) .Figure (15) shows that in acidic medium the adsorption capacity is maximum and decreases with the increase $\mathrm{pH}$ and according to the following $\mathrm{pH}=3$. The $\mathrm{pH}$ of point of zero charge (pHpzc) of $\mathrm{GO} / \mathrm{MgO} \mathrm{NCs}$ was 10.5 and the best $\mathrm{pH}$ is 3 for removal dye below pHpzc so for other adsorption mechanisms between GO/MgO NCs and dye such as hydrogen bonding and $\pi-\pi$ interaction addition to the electrostatic attraction.

\section{Adsorbent Weight}

The effect of adsorbent on percentage removal of dye was examined by taking different quantities of $\mathrm{GO} / \mathrm{MgO}$ NCs ranging from 0.01 to $0.05 \mathrm{gm}$. Our results showed in Figure (16), which the best removal efficiency was obtained at $0.05 \mathrm{gm}^{29}$.

\section{Effect the concentration of dye on adsorption}

Figure (17) shows that the effect concentration of dye on percentage removal of dye by taking different quantities of dye ranging from (5 -30) $\mathrm{ppm}$. Our results showed in figure (8), that the best removal efficiency was obtained at 10 $\mathrm{ppm}^{30}$.

\section{Adsorption Kinetics}

In order to assess the rate of the adsorption for Orange G dye, both pseudo first order and pseudo second order kinetics were applied to the adsorption data ${ }^{31}$.

$$
\begin{aligned}
& \ln \left(q_{e}-q_{t}\right)=\ln q_{e}-k_{1} t \\
& t / q_{t}=1 / k_{2} q e^{2}+\left(1 / q_{e}\right) t
\end{aligned}
$$

Where $\mathrm{q}_{\mathrm{e}}$ and $\mathrm{q}_{\mathrm{t}}(\mathrm{mg} / \mathrm{g})$ are the amounts of dye adsorbed at equilibrium and time $t$ respectively, $k_{1}$ and $k_{2}$ are the rate constant of pseudo first order $\left(\mathrm{min}^{-1}\right)$ and pseudo second order $(\mathrm{g} / \mathrm{mg}$. $\mathrm{min})$. The plots of the equations were examined for best fit by comparing their correlation coefficients $\left(R^{2}\right)$. Figure (11 and 12) shown the straight plots of $\ln \left(\mathrm{q}_{\mathrm{e}^{-}} \mathrm{q}_{\mathrm{t}}\right)$ vs .t and $\mathrm{t} / \mathrm{q}_{\mathrm{t}}$ vs.t, respectively. The correlation coefficients of the linear curves of both kinetics shows that the process more likely follows a second order kinetics. Pseudo-second order model assumes that the rate -limiting step involves chemisorption of adsorbate on the adsorbent. By fitting the experimental data (Figures 18and 19), the adsorption rate constant for each model was calculated and summarized in Table (1). As can be seen from the table, the kinetics data were well fitted by the pseudo-second order, as demonstrated by the higher regression coefficient $\left(R^{2}\right)$ obtained .In addition, the calculated $q_{e}$ values for the pseudo-second order is highly matched with the experimental data as compared with those of the pseudo-first order model. This indicated that the adsorption kinetics of dye on $\mathrm{GO} / \mathrm{MgO}$ NCs was not diffusion controlled ${ }^{32}$.

The adsorption isotherms are to explore the relation between the adsorbate concentration in the bulk (at equilibrium) and the amount adsorbed at the surface. In this study four commonly used isotherm models (Langmuir, Freundlich, Timken, and Dubinin-KaganerRadushkevich) were applied to the experimental data to explain the dye -Nano $\mathrm{GO} / \mathrm{MgO} \mathrm{NCs}$ interaction. The Langmuir isotherm model assume monolayer coverage of the adsorbate over a homogenous adsorbent surface with identical adsorptions sites and their binding energies and neglecting any interactions between adsorbed ions , atoms or molecules ${ }^{33}$ with each molecule adsorbed onto the surface having the same adsorption energy .The Langmuir isotherm is expressed as ${ }^{34}$ :

$$
\frac{\mathrm{C}_{\mathrm{e}}}{\mathrm{Q}_{\mathrm{e}}}=\frac{1}{\mathrm{q}_{\max } \mathrm{k}_{\mathrm{L}}}+\frac{\mathrm{C}_{\mathrm{e}}}{\mathrm{q}_{\max }}
$$

Where $C_{e}$ is the equilibrium concentration of dye $(\mathrm{mg} / \mathrm{L}), q_{\max }, Q_{e}$ are the maximum adsorption capacity corresponding to complete monolayer coverage on the surface $(\mathrm{mg} / \mathrm{g})$ and capacity at equilibrium $(\mathrm{mg} / \mathrm{g})$ respectively and $\mathrm{K}_{\mathrm{L}}$ is Langmuir constant $(\mathrm{L} / \mathrm{mg}){ }^{35}$ related to energy of sorption. Therefore, a plot of $C_{e} / Q_{e}$ versus Ce gives a straight line of slope $1 / \mathrm{q}_{\max }$ and intercept $\left(1 / \mathrm{K}_{\mathrm{L}} \mathrm{q}_{\max }\right)$. From the intercept and slope of the plots in Figure (20). The values of $q_{\max }$ and $K_{L}$ were listed in Table (2), the values of $\mathrm{q}_{\max }$ and $\mathrm{K}_{\mathrm{L}}$ are increased when the solution temperature increased from 20 to $40^{\circ} \mathrm{C}$, indicates that the dye is favorably adsorbed by $\mathrm{GO} / \mathrm{MgO} \mathrm{NCs}$ at lower temperatures, which shows that the adsorption process is endothermic. A dimensionless constant separation factor of Langmuir isotherm $\left(R_{L}\right)$ was also calculated 
using equation ${ }^{36}$ :

$$
R_{L}=1 /\left(1+K_{L} C_{\text {o) }}\right.
$$

The Frenudlich model is a case for multilayer adsorption and adsorption on heterogeneous surface energies and it gives an exponential distribution of active sites. The linear form of this model is represented by:

$$
\ln Q_{e}=\ln K_{F}+1 / n \ln C_{e}
$$

The Frenudlich constants $\mathrm{K}_{\mathrm{F}}$ and $\mathrm{n}$, which respectively indicating the adsorption capacity and the adsorption intensity are calculated from the intercept and slope of plot In $Q_{e}$ versus $\ln \mathrm{C}_{\mathrm{e}}$ respectively, as shown in Figure (21). The intensity of adsorption ( $n$ ) showed low values $(n<1)$; this indicates a very low affinity between adsorbents and adsorbate. The Freundlich constant $\left(\mathrm{K}_{\mathrm{F}}\right)$ decreases with increasing the temperature and this indication for exothermic reaction. The values of $n$ are larger than 1, which represents a favorable removal condition ${ }^{(37) .}$

A more common isotherm than Langmuir is the Dubinin-Kaganer -Radushkevich (DKR) model was proposed by Dubinin which does not assume a homogenous surface of surface of sorbent .It is applied to determine the adsorption mechanism (physical or chemical). The linear form of (DKR) as follows ${ }^{38}$ :

$$
\ln Q_{e}=\ln q_{\max }-\beta \varepsilon^{2}
$$

Where $\mathrm{q}_{\max }$ is the maximum sorption capacity $(\mathrm{mg} / \mathrm{g}), \boldsymbol{\beta}$ is the activity coefficient related to mean sorption energy $\left(\mathrm{mol}^{2} / \mathrm{J}^{2}\right)$, and $\boldsymbol{\varepsilon}$ is the Polanyi potential defined as:

$$
\varepsilon=R T \ln \left(1+1 / C_{e}\right)
$$

Where $R$ is the gas constant $(\mathrm{KJ} / \mathrm{mol}$. K). The slope of the plot of In qe versus $\varepsilon^{2}$ gives $\beta$ and the intercept yields the sorption capacity $q_{\max }$, as shown in Figure (22). Prognostication of the adsorption mechanism (physical or chemical sorption) can be done by calculating the value of the mean sorption energy, $E(\mathrm{~J} / \mathrm{mol})$ from the relation ${ }^{39}$ :

$$
E=(-2 \beta)^{-0.5}
$$

The values of $\beta, q_{\max }, E$ and $R^{2}$ as a function of temperature are listed in Table (2). If the values of $E$ were less than $8 \mathrm{~kJ} / \mathrm{mol}$, the mechanism maybe a physical adsorption, While $E$ values between $8-16 \mathrm{~kJ} / \mathrm{mol}$ assumes the adsorption to be controlled by ion exchange and $E$ greater than $16 \mathrm{~kJ} / \mathrm{mol}$ presume a particle diffusion mechanism (chemical process).It can be observed that the values of $E$ may be physical (electrostatic) in nature. The Temkin isotherm in the linear form has been used as the following:

$$
\mathrm{Q}_{\mathrm{e}}=\mathrm{BlnK}_{\mathrm{T}}+\mathrm{BlnC}_{\mathrm{e}}
$$

Where $B=R T / b$ is related to heat of adsorption of adsorption $(\mathrm{J} / \mathrm{mol}), \mathrm{K}_{\mathrm{T}}$ is equilibrium binding constant $(\mathrm{L} / \mathrm{gm}), \mathrm{R}$ is the gas constant $(8.314 \mathrm{~J} / \mathrm{mol}$. $\mathrm{K})$.Both $\mathrm{K}_{\mathrm{T}}$ and $\mathrm{B}$ are calculated (as shown in Table (5)) from the intercept and the slope of curve between $\ln C e$ and $\mathrm{Qe}$ as in Figure (23).As presented in Table (2), the adsorption of Orange $\mathrm{G}$ dye on $\mathrm{GO} / \mathrm{MgO} \mathrm{NCs}$ nanoparticles was fit to Langmuir isotherm by higher correlation factor $\left(R^{2}\right)$ values. The results show what is otherwise based on the correlation coefficient data ${ }^{40}$.The values of dimensionless sorption factor $\left(\mathrm{K}_{\mathrm{L}}\right)$ were close to zero and this indication for favorable adsorption. The intensity of adsorption ( $n$ ) showed low values $(n<1)$; this indicates a very low affinity between adsorbents and adsorbate ${ }^{37}$. The Freundlich constant $\left(\mathrm{K}_{\mathrm{F}}\right)$ decreases with increasing the temperature and this indication for exothermic reaction. In isotherm Dubinin (DKR), the energy equation gives us a perception of the adsorption mechanism. ( $\mathrm{E}<8 \mathrm{KJ} / \mathrm{mol})$ indicates that the physical force influence adsorption and that $(E>16)$ indicates the spread of molecules and when (E) is between (8-16) indicates that adsorption is directed by ion exchange, and the values of (B) less than $(40 \mathrm{~kJ} / \mathrm{mol})$ this indication for physical adsorption ${ }^{30}$.

\section{Thermodynamics parameters}

The thermodynamics parameters $\left(\Delta \mathrm{H}^{\circ}, \Delta \mathrm{G}^{\circ}, \Delta\right.$ $S^{\circ}$ ) of the removal of dye on $\mathrm{GO} / \mathrm{MgO} \mathrm{NCs}$ were calculated according to the following relations:

$$
\begin{aligned}
& K_{C}=A e^{-\Delta H / R T} \\
& \ln X_{m}=-\frac{\Delta H}{R T}+K
\end{aligned}
$$

Where $\ln X_{m}$ is the natural logarithm for greatest amount adsorbed $(\mathrm{mg} / \mathrm{g}), \mathrm{K}$ is the constant of Van't Hoff equation, $R$ is the universal gas constant $\left(8.314 .10^{-3} \mathrm{~J} / \mathrm{mol}^{-\mathrm{K}^{-1}}\right)$ and $T$ is the temperature in Kelvin.

$$
\Delta \mathbf{G}^{\circ}=-\mathbf{R T} \ln \mathbf{K}
$$




$$
\begin{aligned}
& \mathbf{K}=\frac{\mathbf{Q}_{\mathrm{e} \times \mathbf{m}}}{\mathrm{C}_{\mathrm{e}} \times \mathbf{V}} \\
& \Delta \mathbf{G}^{\circ}=\Delta \mathbf{H}-\mathbf{T} \Delta \mathbf{S}^{\circ} \\
& \Delta \mathbf{S}^{\circ}=\frac{\Delta \mathbf{H}-\Delta \mathbf{G}^{\circ}}{\mathrm{T}}
\end{aligned}
$$

The value $\Delta \mathrm{H}^{\circ}$ was calculated from the slope and intercept of the Van't Hoff plots (the plots of In $X_{m}$ versus $1 / T$ ) (Figure (24)) and listed in Table (3) ${ }^{41}$.The value of $\Delta \mathrm{H}^{\circ}$ was positive for by meaning the adsorption processes is endothermic, the value of $\Delta G$ is negative this indicate that the adsorbent may be can happened spontaneously while the value of $\Delta S$ is positive and that meaning the movement of molecules isn't restricted.

\section{CONCLUSION}

Based upon the experimental results of this study show that Nano-GO/MgO NCs can be considered as an adsorbent for the treatment of Orange $\mathrm{G}$ dye from waste water. In batch experimental, the influence of contact time, initial dye concentration, amount of $\mathrm{GO} / \mathrm{MgO}$ NCs, temperature were show to be effective. The removal of dye is an exothermic process. It was found that the pseudo -second order model might have followed by the adsorption process as supported by correlation coefficients of the linear plots, and also $q_{c a l a}$ were very close to the $q_{\text {exp }}$ for the pseudo second order rate kinetics. The isotherm study indicates four isotherms models. Adsorption data was fit to Freundlich isotherm, the Freundlich constant $\left(\mathrm{k}_{\mathrm{F}}\right)$ decreases with increasing the temperature and this indication for exothermic. In isotherm Dubinin (DKR), the energy equation gives us a perception of the adsorption mechanism. (E $<8 \quad \mathrm{KJ} / \mathrm{mol})$ indicates that the physical force influence.

\section{ACKNOWLEDGMENTS}

Authors wish to thank department chemistry, college science, Diyala university for providing instrument facilities to carry out the research work.

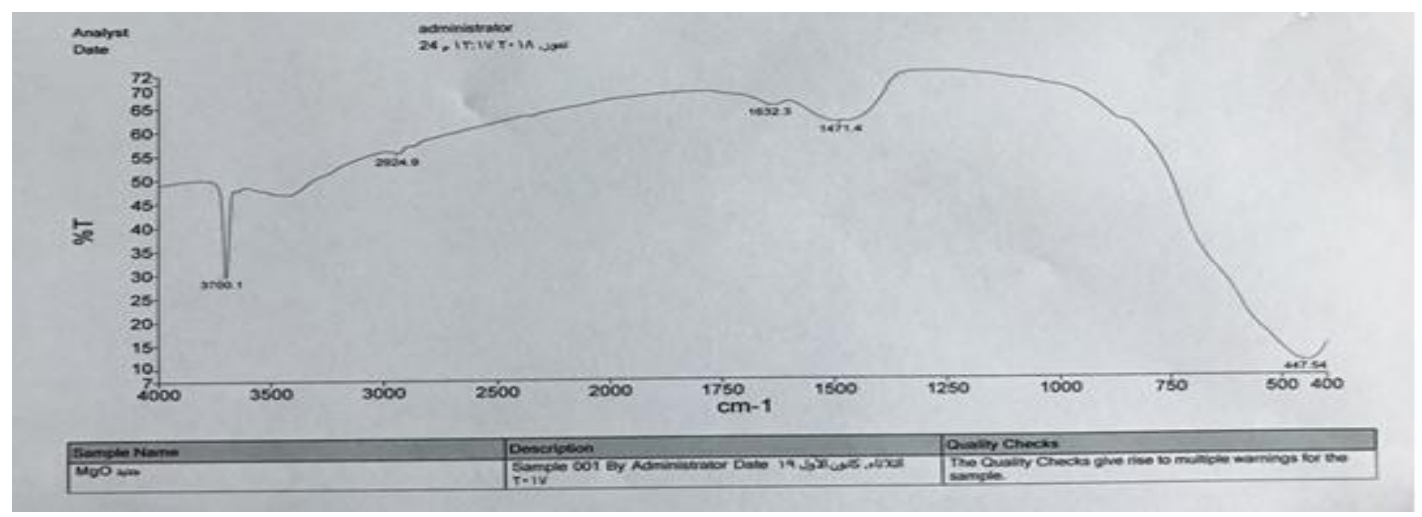

Fig. 1: FTIR spectra of MgO Nanoparticles

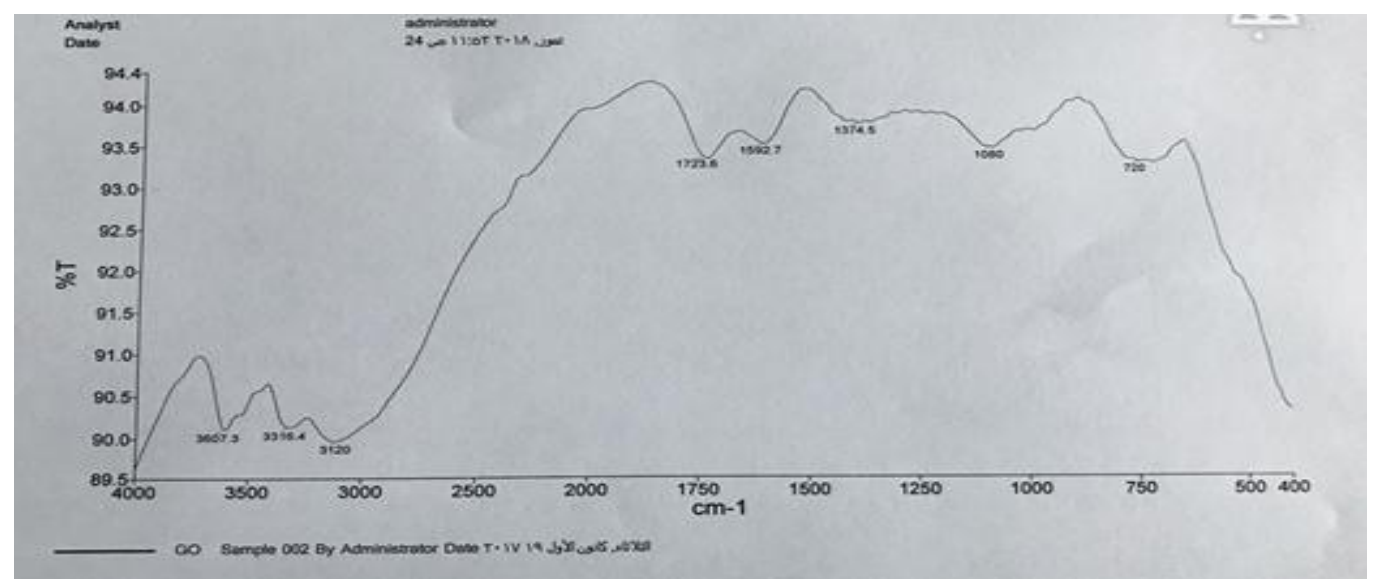

Fig. 2: FTIR spectra of GO 


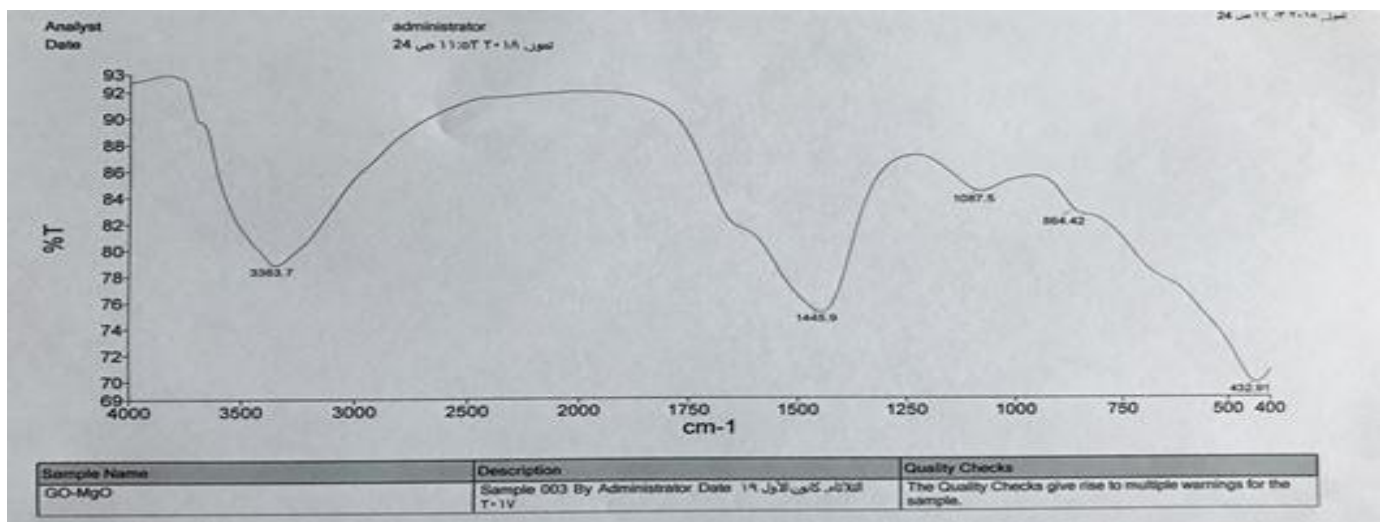

Fig. 3: FTIR spectra of GO/MgO NCS

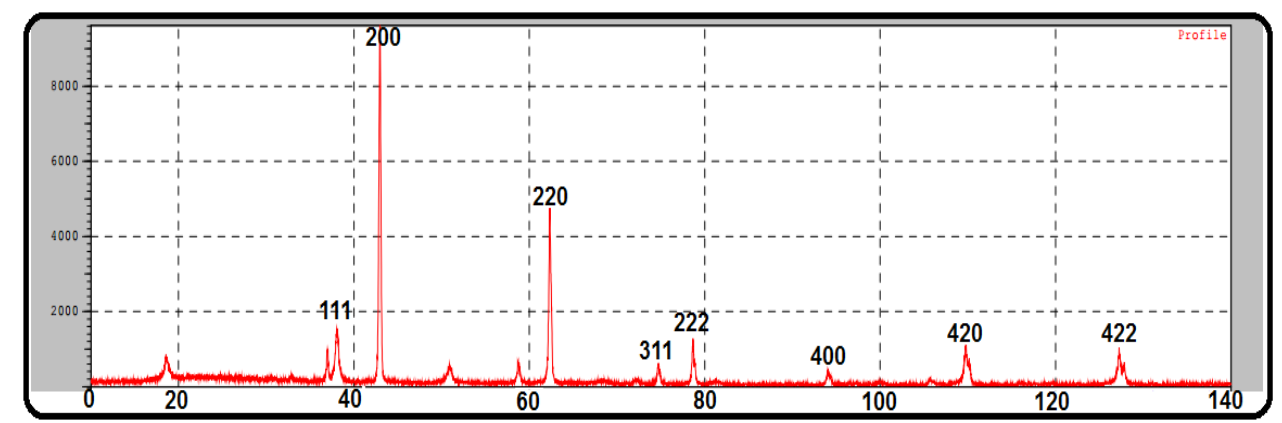

Fig. 4: XRD pattern of $\mathrm{MgO}$ nanoparticles

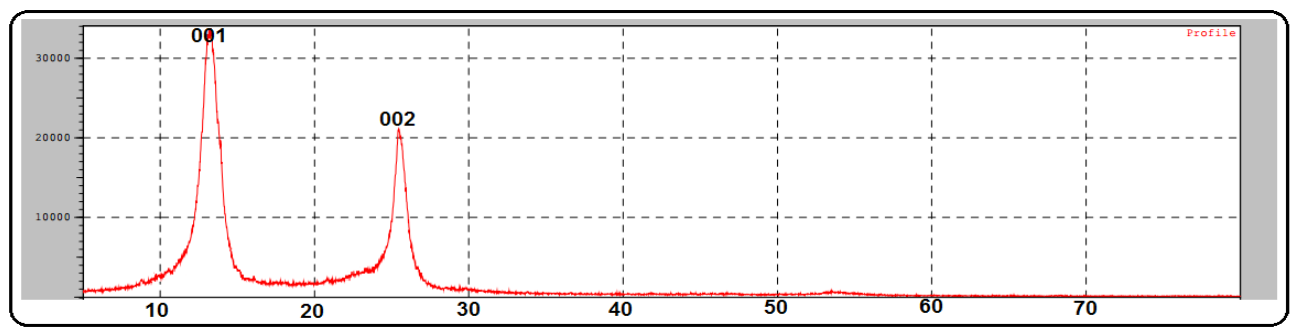

Fig. 5: X-ray diffraction spectra of the GO

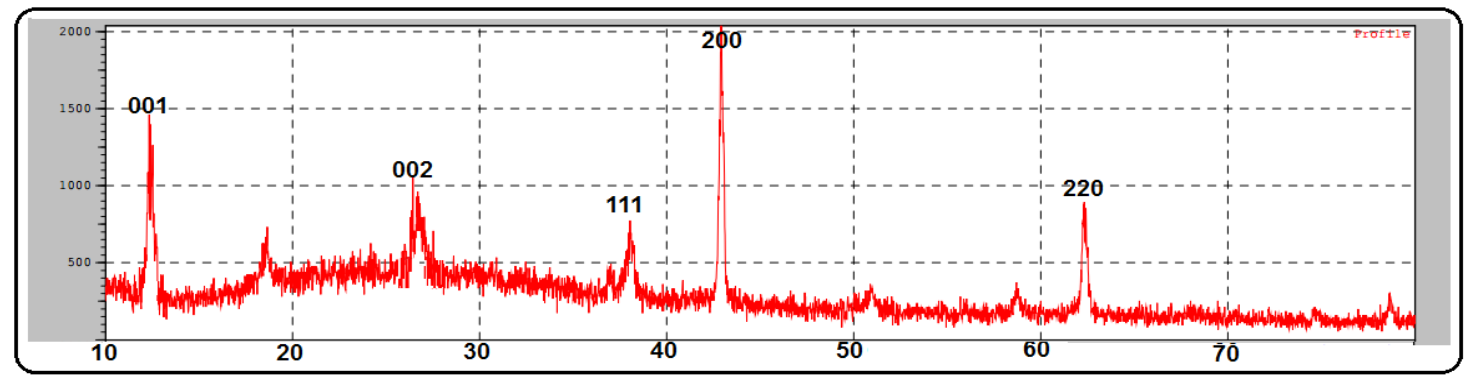

Fig. 6: X- ray diffraction of the $\mathrm{GO} / \mathrm{MgO} \mathrm{NC}$ s 


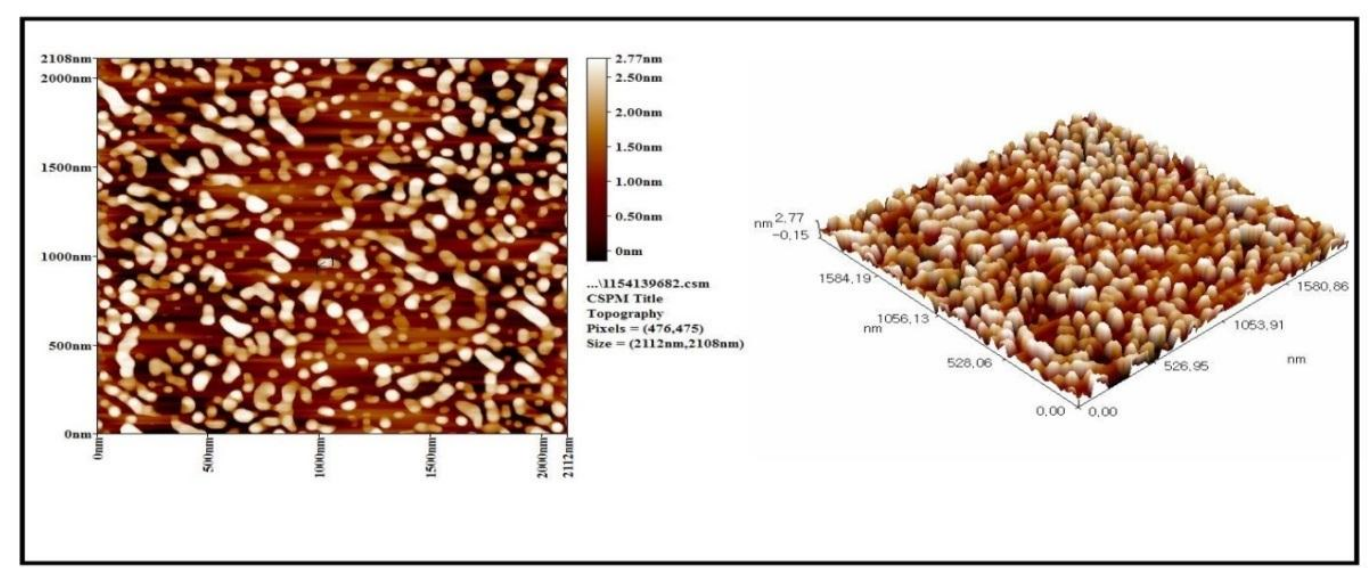

Fig. 7: AFM images of MgO nanoparticls

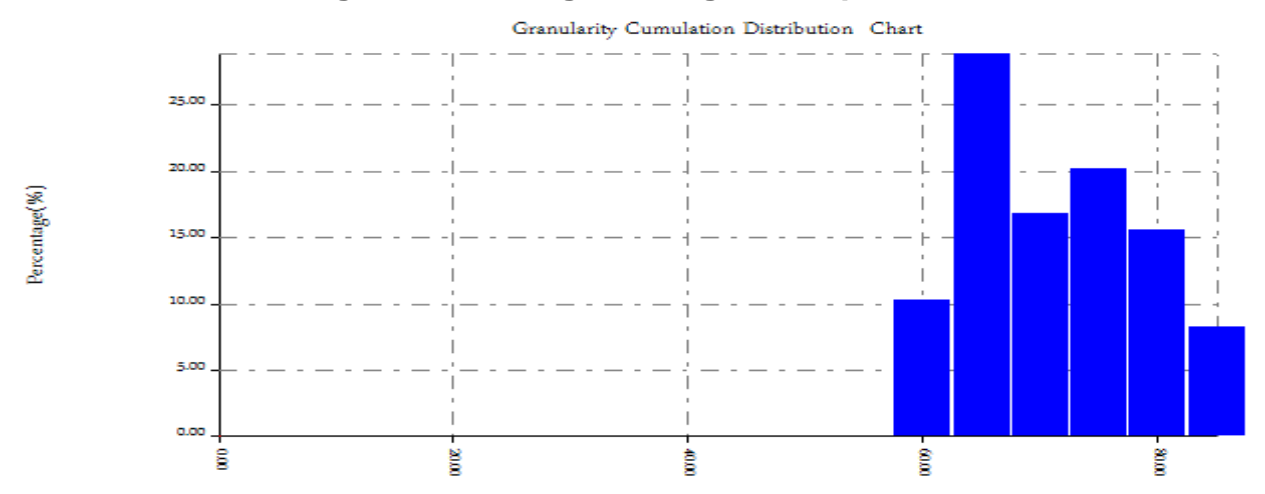

Diameter(nm)

Fig. 8: Particle size distribution MgO Nano particles

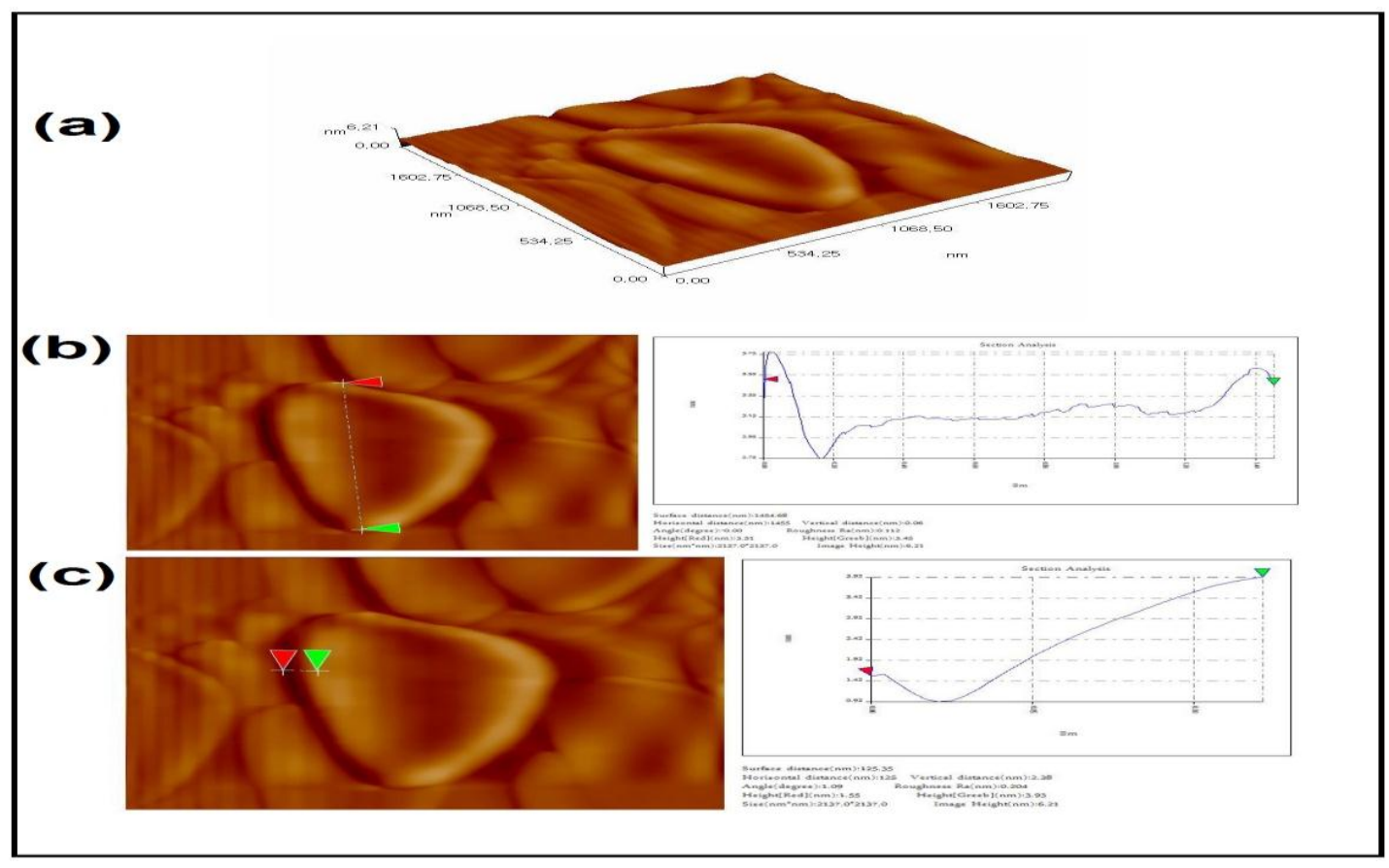

Fig. 9: AFM images of GO Nano sheet percentage of MgO nanoparticle 


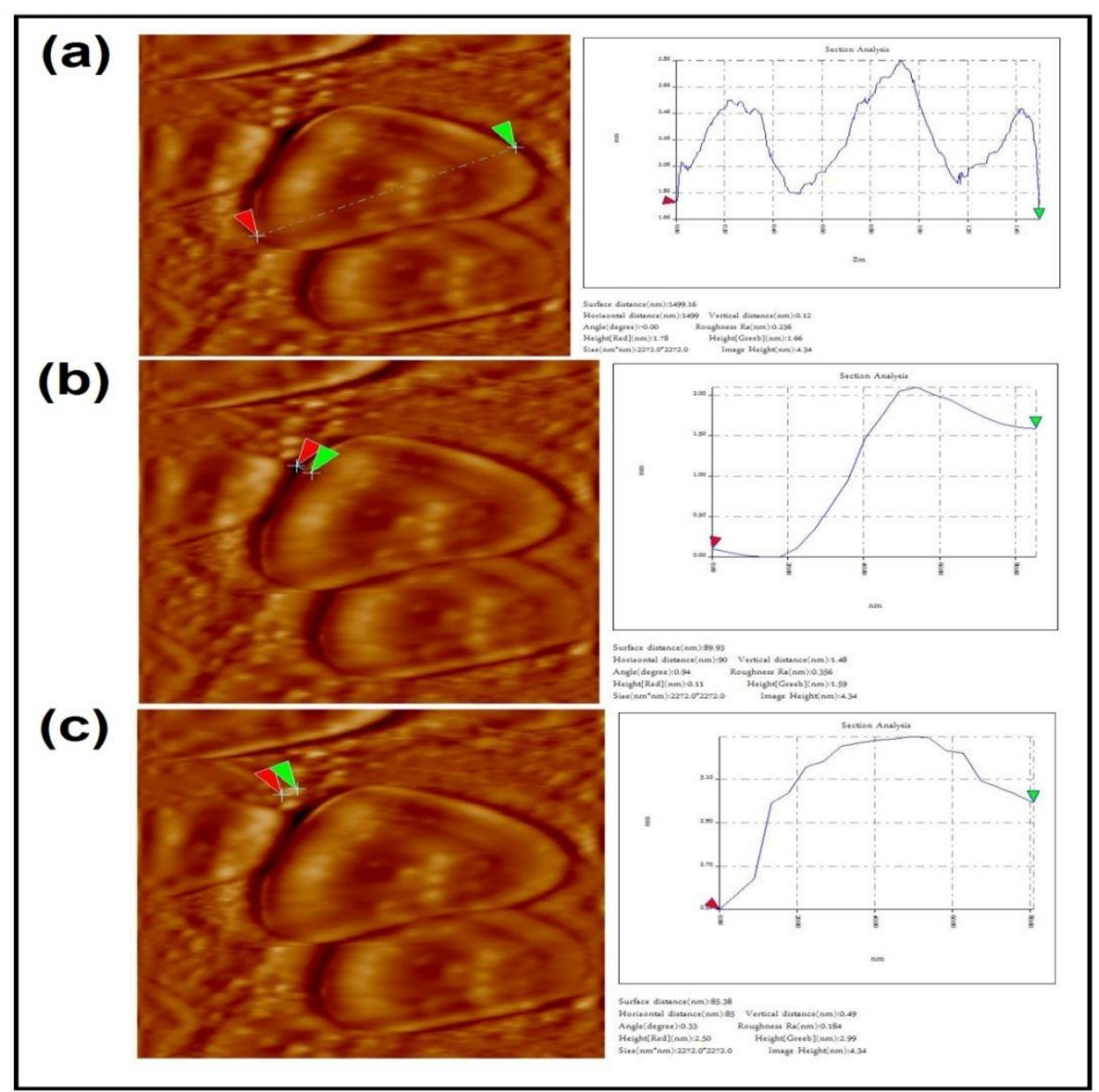

Fig. 10: AFM images of GO/ MgO NCs

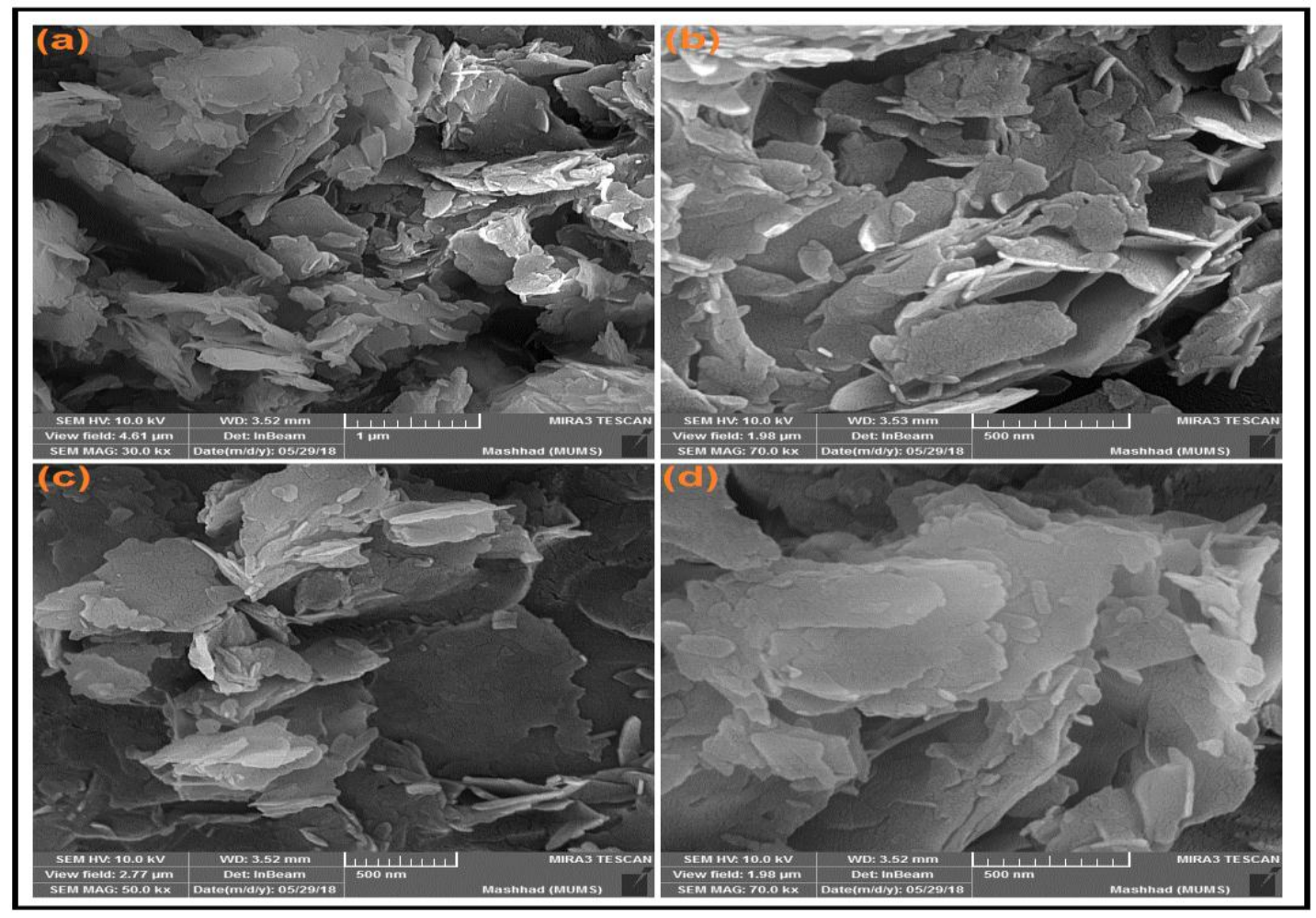

Fig. 11: SEM images with different magnification power of MgO nanoparticle 


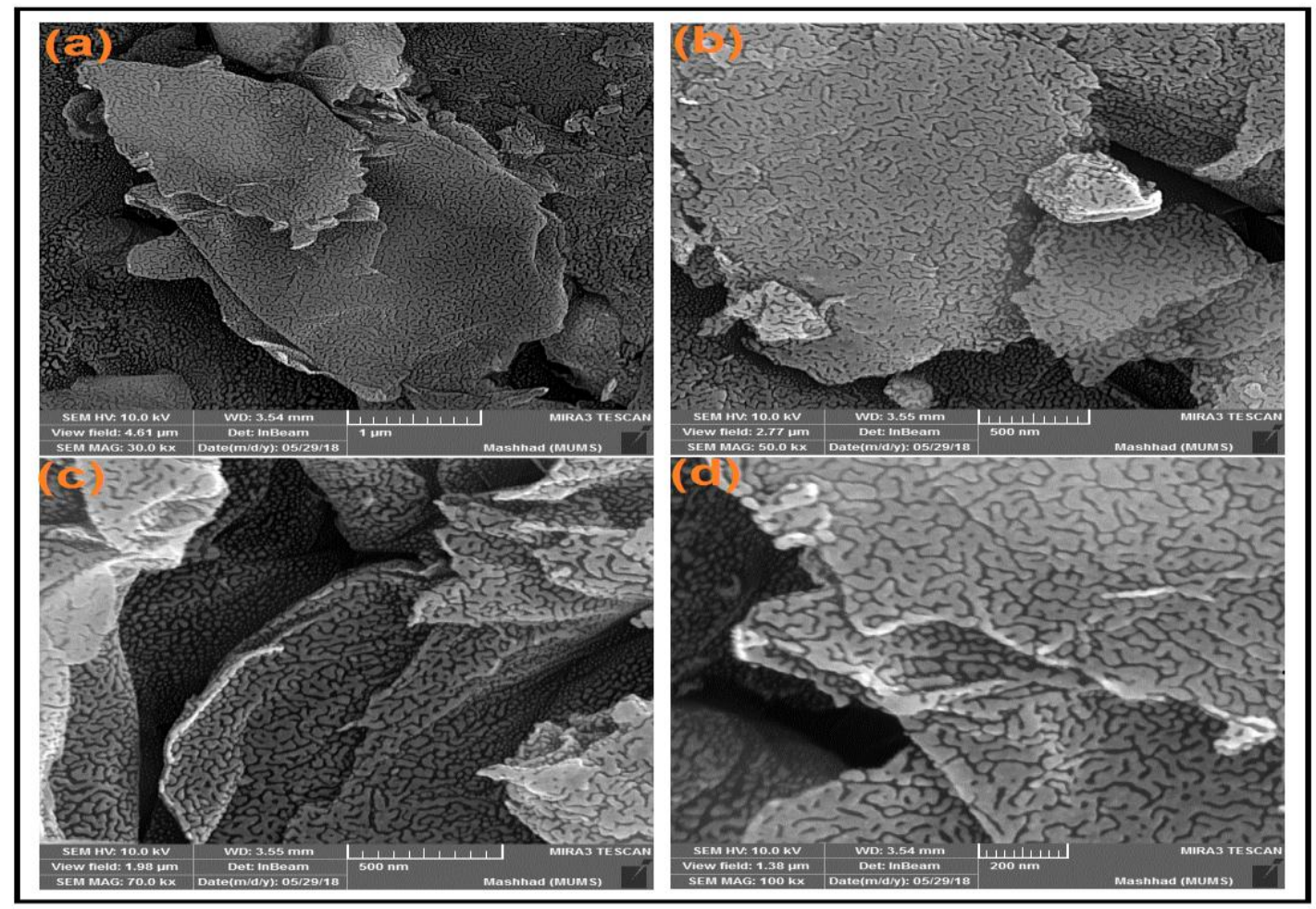

Fig. 12: SEM images with different magnification power of GO

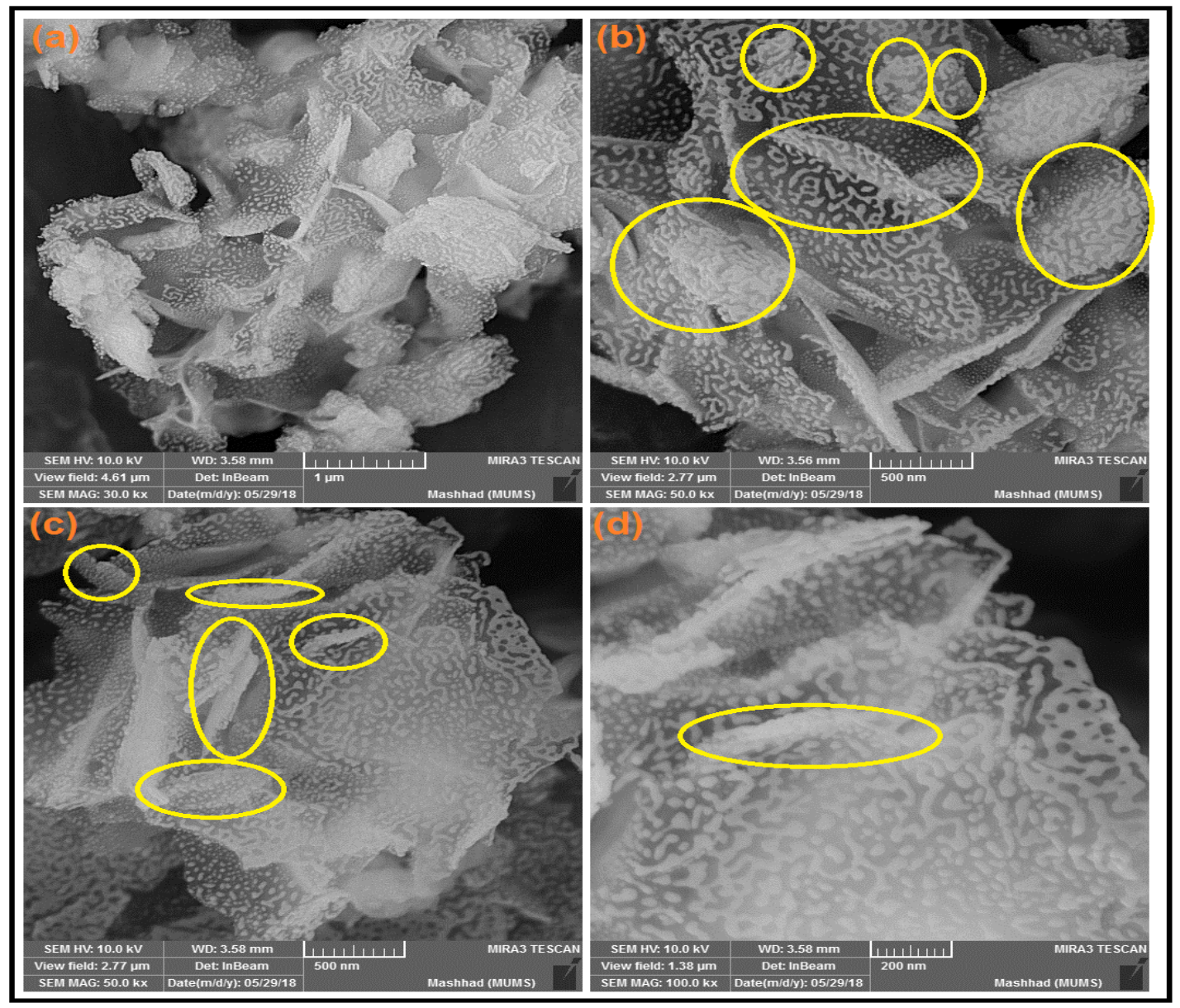

Fig. 13: SEM with different magnification power of GO/MgO NCs 


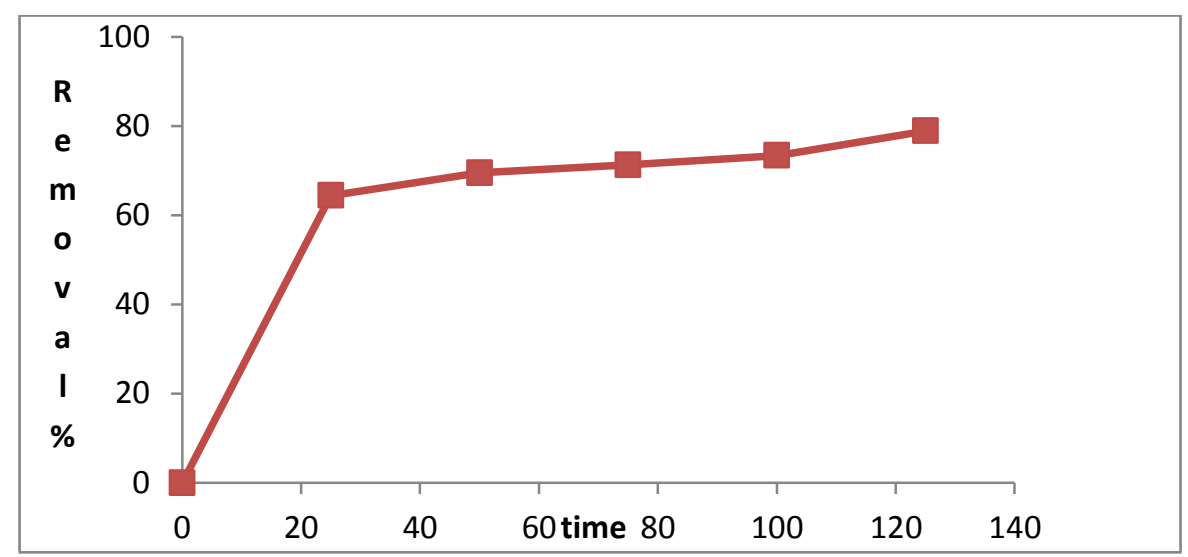

Fig. 14: Effect of equilibrium time for adsorption of Orange $G$ dye on (GO/MgO NCs) nanoparticles

at $\left(25^{\circ} \mathrm{C}, \mathrm{C}_{0}=30 \mathrm{ml}\right.$ of $10 \mathrm{ppm}$, dose $0.04 \mathrm{~g}$ and $\left.\mathrm{pH}=8\right)$

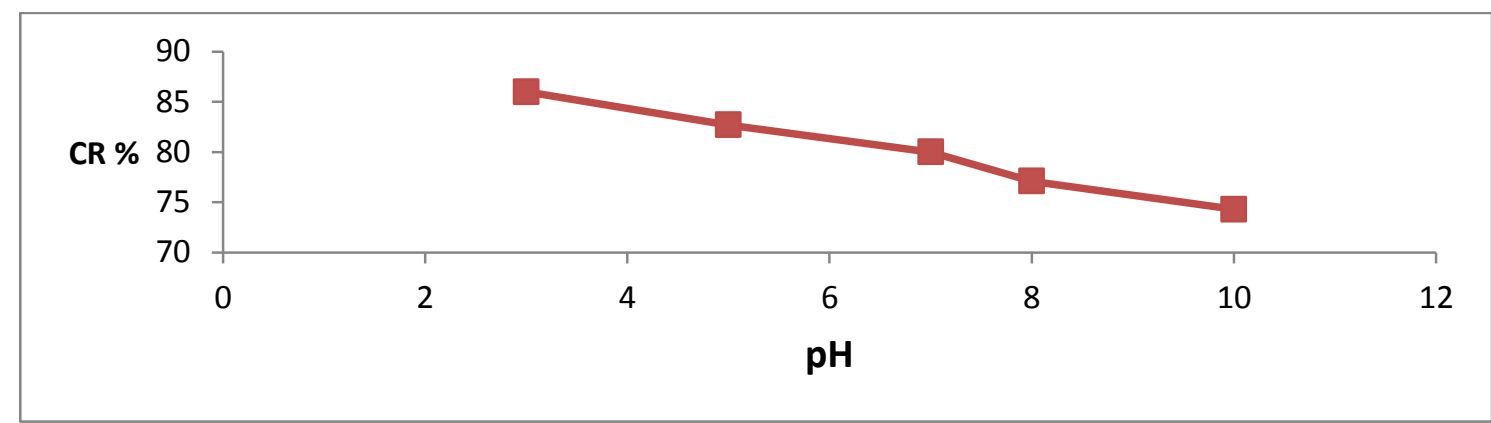

Fig. 15: Effect of pH on the adsorption of Orange $\mathrm{G}$ dye on $\mathrm{GO} / \mathrm{MgO} \mathrm{NCs}$ nanoparticles at

$\left(25^{\circ} \mathrm{C} .30 \mathrm{ml}\right.$ of $10 \mathrm{ppm}$ dye and dose $\left.0.04 \mathrm{gm}\right)$

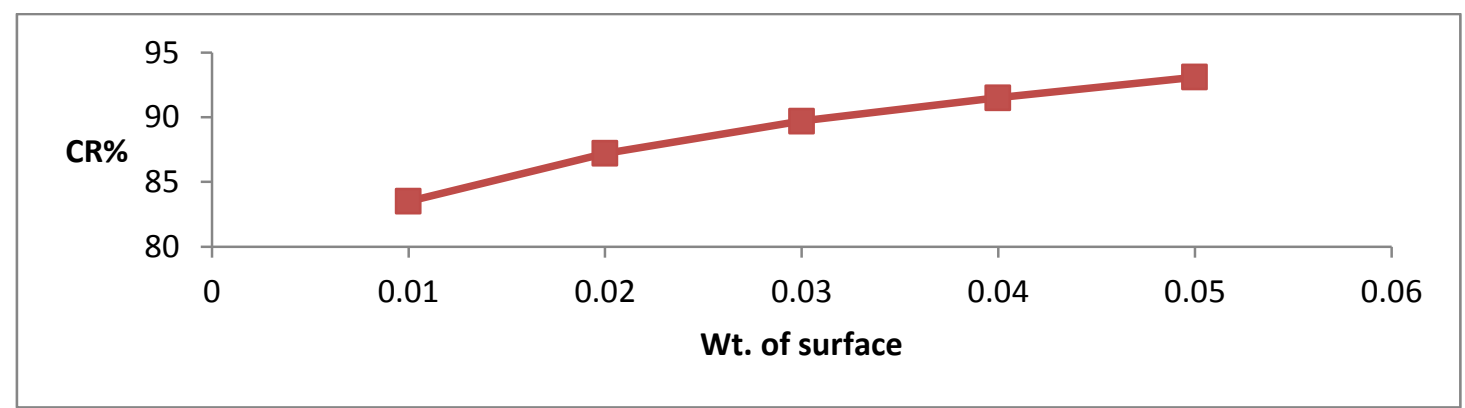

Fig. 16: Effect of adsorbents weight on the adsorption of Orange $\mathrm{G}$ dye on (GO/MgO NCs) nanoparticles at $\left(25^{\circ} \mathrm{C}, \mathrm{C}_{\mathrm{o}}=30 \mathrm{ml}\right.$ of $10 \mathrm{ppm}$ and $\left.\mathrm{pH}=3\right)$

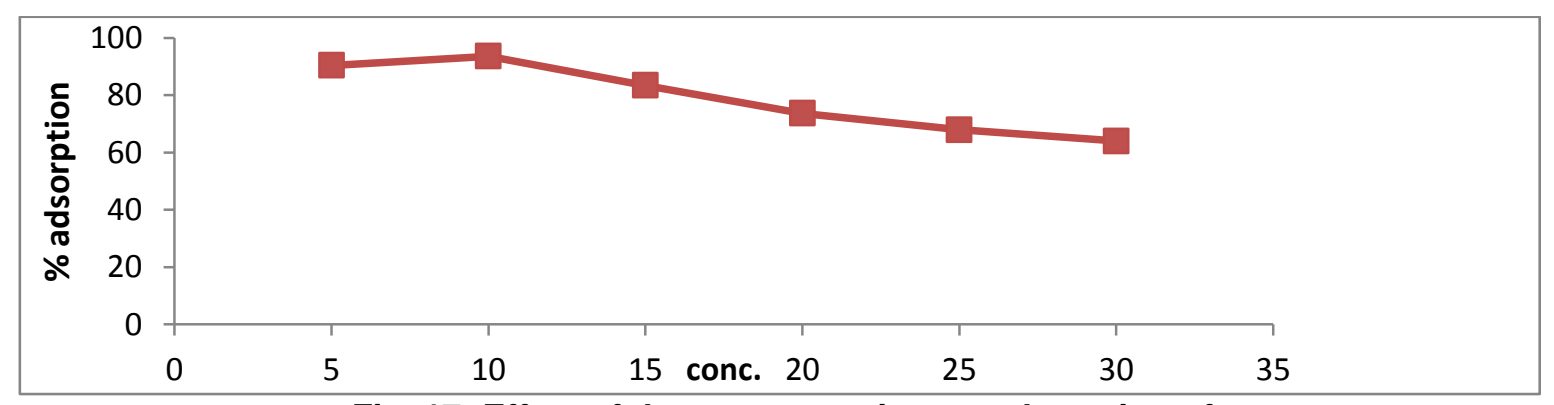

Fig. 17: Effect of dye concentration on adsorption of

Orange $\mathrm{G}$ dye on (GO/MgO NCs) nanoparticles at $\left(25^{\circ} \mathrm{C}\right.$, dose $0.05 \mathrm{gm}$ and $\mathrm{pH}=3$ ) 


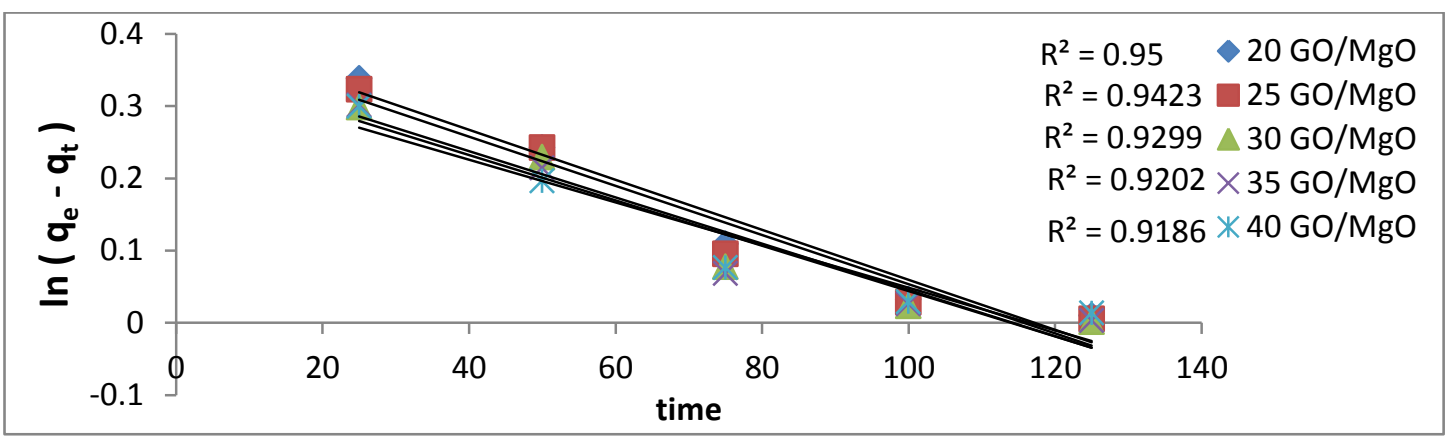

Fig. 18: plot of pseudo-first order model of Orange G dye on GO/MgO NCs

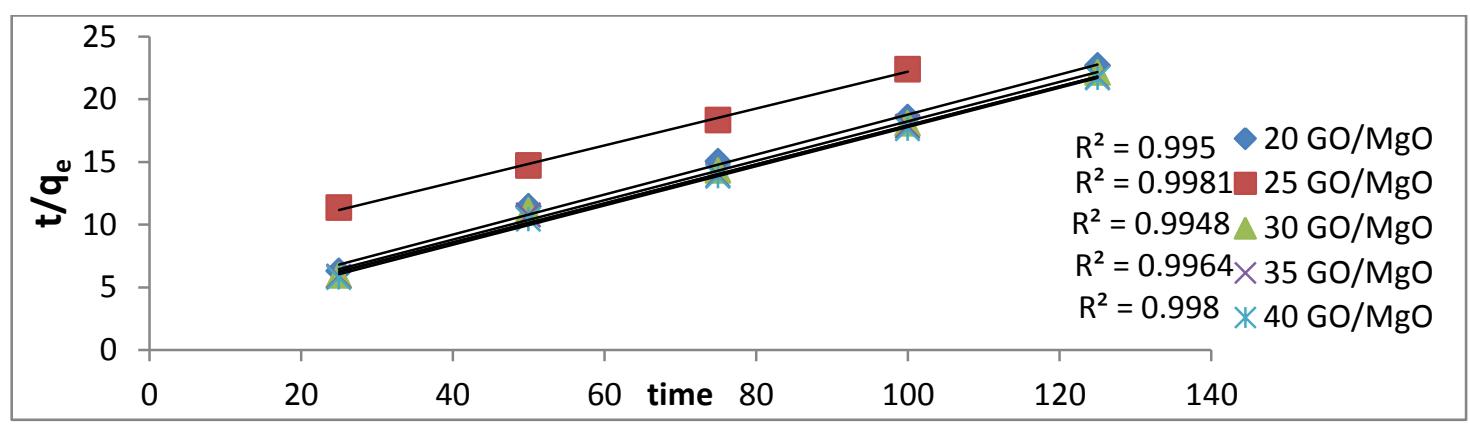

Fig. 19:plot of pseudo -second order model of of Orange $\mathrm{G}$ dye on GO/MgO NCs nanoparticles at different temperature

Table 1: Kinetics parameters for adsorption of Orange G dye on GO/MgO NCs

\begin{tabular}{|c|c|c|c|c|c|c|c|c|}
\hline $\mathrm{C}_{\mathrm{o}}$ & \multirow[b]{2}{*}{$\mathrm{T}\left({ }^{\circ} \mathrm{C}\right)$} & \multicolumn{3}{|c|}{ Pseudo first order } & \multirow[b]{2}{*}{$\mathbf{R}^{2}$} & \multicolumn{3}{|c|}{ Pseudo second order } \\
\hline \multirow{6}{*}{$\begin{array}{c}10 \\
\text { Ppm }\end{array}$} & & $q_{e}(\exp )$. & $\mathrm{K}_{1} \mathrm{Min}^{-1}$ & $\begin{array}{c}q_{\mathrm{e}} \\
\text { (calc.) }\end{array}$ & & $\begin{array}{c}q_{e} \\
\text { (calc.) }\end{array}$ & $\begin{array}{c}\mathrm{K}_{2} \\
\text { g.mg } \\
\mathrm{m}^{1} \cdot \mathrm{min}^{-1}\end{array}$ & $\mathbf{R}^{2}$ \\
\hline & 20 & 5.57 & 0.0035 & 4.43 & 0.95 & 5.57 & 0.0089 & 0.995 \\
\hline & 25 & 5.61 & 0.0034 & 4.39 & 0.942 & 5.61 & 0.0028 & 0.998 \\
\hline & 30 & 5.66 & 0.0032 & 4.34 & 0.929 & 5.66 & 0.0097 & 0.994 \\
\hline & 35 & 5.76 & 0.0031 & 4.24 & 0.920 & 5.76 & 0.0101 & 0.996 \\
\hline & 40 & 5.84 & 0.003 & 4.16 & 0.918 & 5.84 & 0.0110 & 0.998 \\
\hline
\end{tabular}

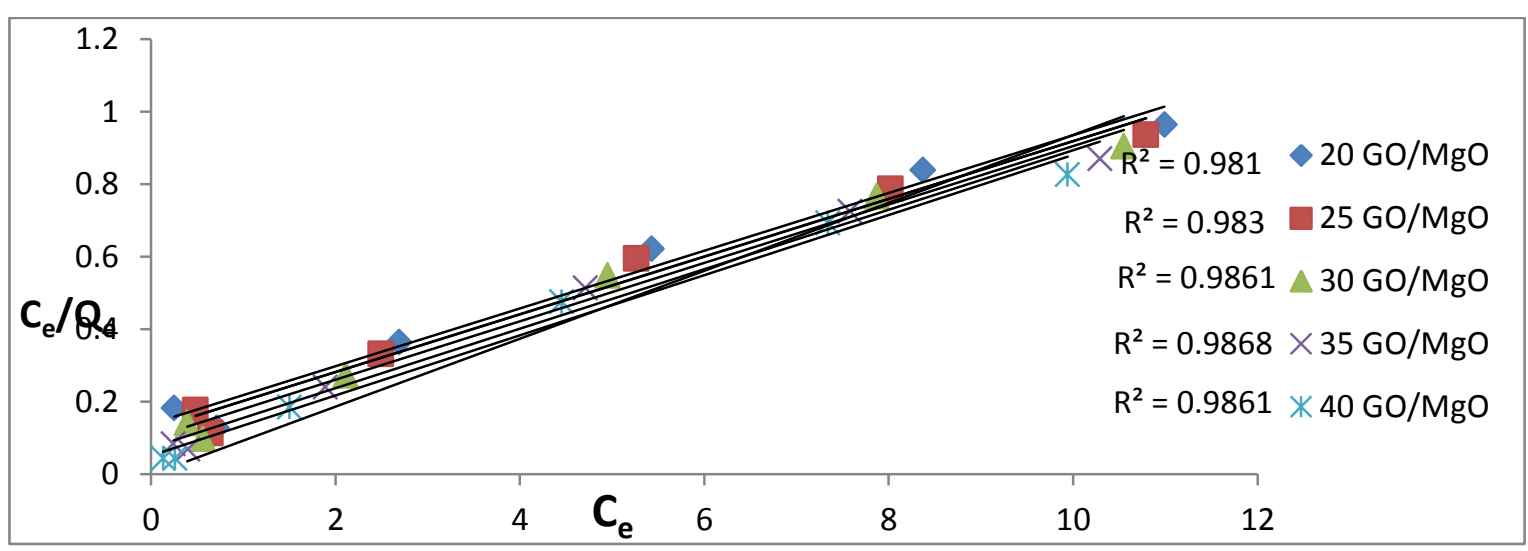

Fig. 20: Isotherm Langmuir for Orange G dyes on GO/MgO NCs nanoparticles 


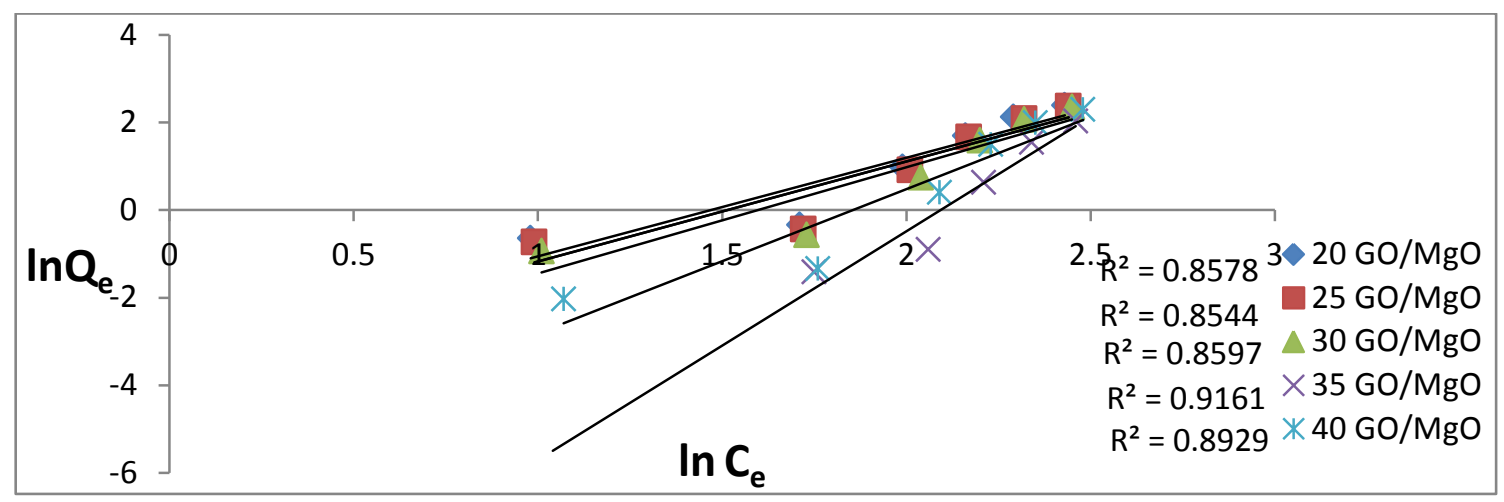

Fig. 21: Isotherm Freundlich for Orange $G$ dyes at different concentrations on GO/MgO NCs

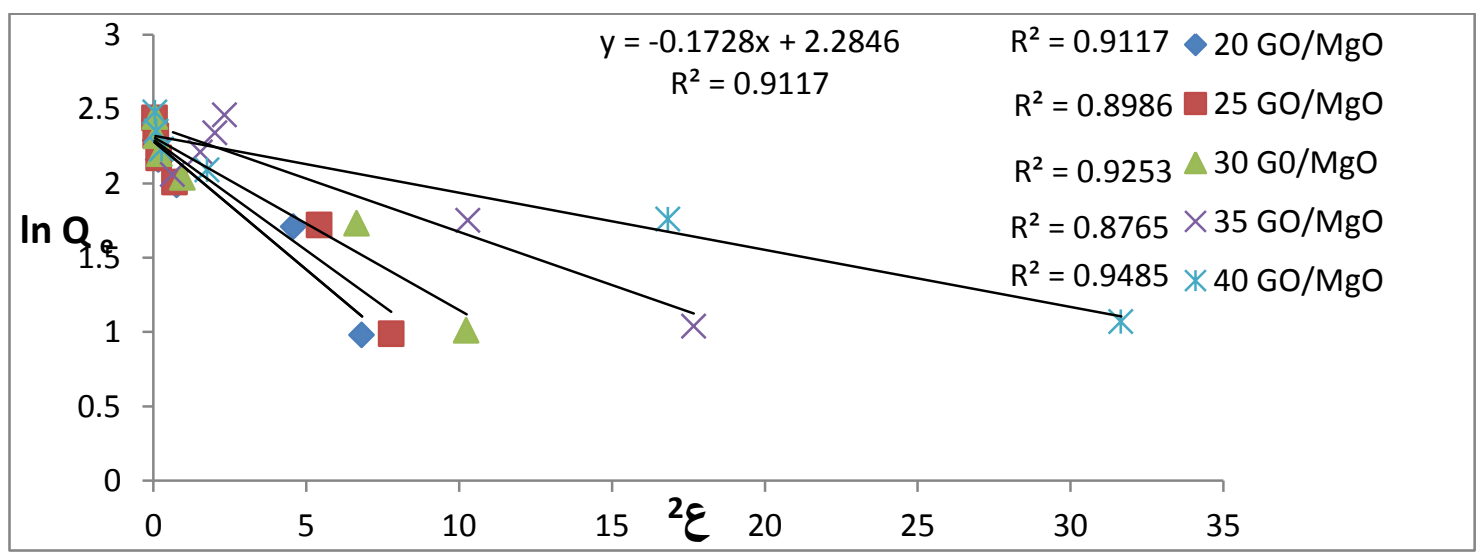

Fig. 22: Isotherm Dubinin (DKR) for Orange G dye on GO/MgO NCs

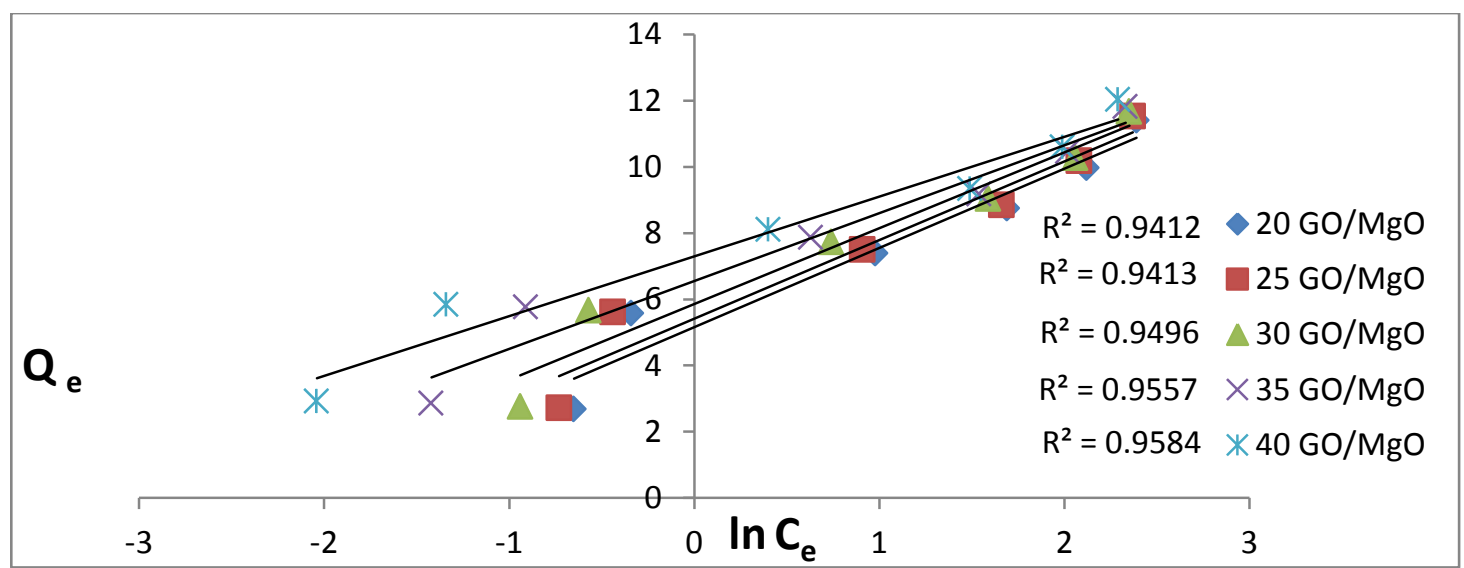

Fig. 23: Isotherm Temkin

for Orange $\mathrm{G}$ dye on $\mathrm{GO} / \mathrm{MgO} \mathrm{NCs}$

Table 2: The calculated adsorption

parameters of the four used isotherms

\begin{tabular}{|c|c|c|c|c|c|c|c|}
\hline \multicolumn{9}{|c|}{ Langmuir } & \multicolumn{3}{c|}{ Freundlich } \\
\hline $\mathbf{T}\left({ }^{\circ} \mathbf{C}\right)$ & $\mathbf{K}_{\mathbf{L}}$ & $\mathbf{R}^{\mathbf{2}}$ & $\mathbf{q}_{\max }$ & $\mathbf{R}_{\mathbf{L}}$ & $\mathbf{K}_{\mathbf{F}}$ & $\mathbf{1 / n}$ & $\mathbf{R}^{\mathbf{n}}$ \\
\hline $\mathbf{2 0}$ & $\mathbf{0 . 5 7 2 2}$ & 0.9754 & 5.57 & $\mathbf{0 . 0 6 3 6}$ & 3.300 & 2.248 & 0.857 \\
\hline $\mathbf{2 5}$ & $\mathbf{0 . 6 4 3 2}$ & 0.9092 & 5.61 & $\mathbf{0 . 0 6 0 8}$ & 3.455 & 2.281 & 0.854 \\
\hline $\mathbf{3 0}$ & $\mathbf{0 . 8 0 2 5}$ & 0.9808 & 5.66 & $\mathbf{0 . 0 5 5 4}$ & 3.874 & 2.423 & 0.859 \\
\hline $\mathbf{3 5}$ & $\mathbf{1 . 1 0 5 2}$ & 0.9806 & 5.76 & $\mathbf{0 . 0 4 7 5}$ & 10.908 & 5.217 & 0.916 \\
\hline $\mathbf{4 0}$ & $\mathbf{1 . 6 0 0 3}$ & 0.9804 & 5.84 & $\mathbf{0 . 0 3 8 4}$ & 6.112 & 3.294 & 0.892 \\
\hline
\end{tabular}




\begin{tabular}{|c|c|c|c|c|c|c|}
\hline \multicolumn{5}{|c|}{ (DKR) } & \multicolumn{3}{c|}{ Temkin } \\
\hline $\boldsymbol{\beta}$ & $\mathbf{q}_{\max }$ & $\mathbf{E}$ & $\mathbf{R}^{\mathbf{2}}$ & $\mathbf{K}_{\mathbf{T}}$ & $\mathbf{B}$ & $\mathbf{R}^{2}$ \\
\hline-0.1728 & 2.284 & 0.586 & 0.911 & 5.154 & 2.392 & 0.941 \\
\hline-0.1489 & 2.293 & 0.544 & 0.898 & 5.408 & 2.377 & 0.941 \\
\hline-0.1164 & 2.311 & 0.481 & 0.925 & 5.854 & 2.293 & 0.949 \\
\hline-0.0715 & 2.387 & 0.376 & 0.876 & 6.554 & 2.048 & 0.955 \\
\hline-0.0384 & 2.320 & 0.277 & 0.948 & 7.296 & 1.802 & 0.958 \\
\hline
\end{tabular}

Table 3: Values of thermodynamic functions for adsorption Orange $\mathrm{G}$ dye on (GO/MgO NCs)

\begin{tabular}{|c|c|c|c|c|c|c|}
\hline $\begin{array}{c}\mathrm{C}_{\mathrm{e}} \\
(\mathrm{mg} / \mathrm{L})\end{array}$ & $\begin{array}{c}\text { Thermodynamic } \\
\text { function }\end{array}$ & $20^{\circ} \mathrm{C}$ & $25^{\circ} \mathrm{C}$ & $30^{\circ} \mathrm{C}$ & $35^{\circ} \mathrm{C}$ & $40^{\circ} \mathrm{C}$ \\
\hline \multirow{3}{*}{ 30ppm } & $\Delta$ H kJ.mol $^{-1}$ & \multicolumn{5}{|c|}{1.738} \\
\hline & $\Delta G$ kJ.mol ${ }^{-1}$ & -0.08 & -0.16 & -0.25 & -0.35 & -0.49 \\
\hline & $\Delta S$ J.mol ${ }^{-1} \mathrm{~K}^{-1}$ & 6.17 & 6.34 & 6.53 & 6.75 & 7.09 \\
\hline
\end{tabular}

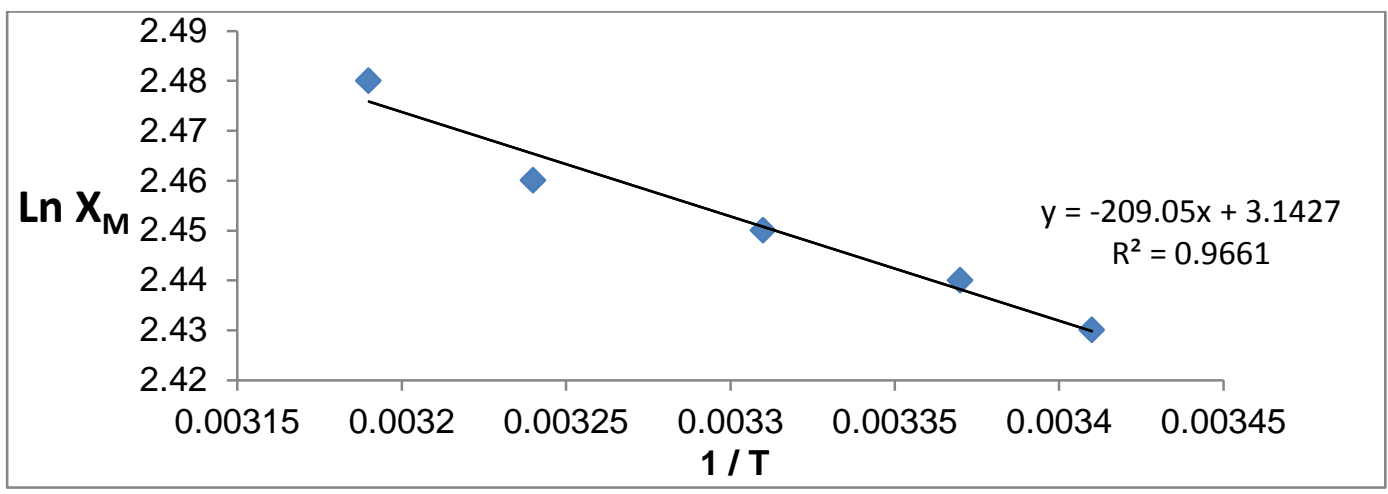

Fig. 24: Values of greatest amounts adsorbed $\left(\ln X_{m}\right)$ for Orange $\mathrm{G}$ dye on (GO/MgO NCs) at different temperatures (293-318 K)

\section{REFERENCES}

1. Li YH, Liu T, Du Q, Sun J, Xia Y, Wang $Z$ and $W u$ D. Adsorption of cationic red $X-G R L$ from aqueous solutions by graphene: equilibrium, kinetics and thermodynamics study. Chemical and Biochemical Engineering Quarterly. 2012;25(4):483-491.

2. Tiwari JN, Le $\mathrm{NH}$, Kemp $\mathrm{KC}$, Timilsina R and Kim KS. Reduced graphene oxide-base hydrogels for the efficient capture of dye pollutants from aqueous solutions, Carbon.2013; 56:173-182.

3. Mohammed AF, Zaid HM and Marwa SF. synthesis and characterization of $\mathrm{TiO} 2 / \mathrm{Au}$ nanocomposite using UV-irradiation method and its photocatalytic activity to degradation of methylene blue. 2018;30(5):1142-1146.

4. Kalyani DC, Telke AA, Dhanve RS and Jadhav JP. Ecofriendly biodegradation and detoxification of Reactive Red 2 textile dye by newly isolated Pseudomonas sp. SUK1. Journal of Hazardous Materials. 2009; 163(2):735-742.

5. Zaid HM, Nuha FA and Aklas AA. effect of solvent on size of copper oxide nanopaerticles fabrication using photolysis method. Asian journal of chemistry. 2018;30:223225.

6. Deriszadeh ALI, Husein $M M$ and Harding TG. Produced water treatment by micellar-enhanced ultrafiltration. Environmental science \& technology. 2010;44(5):17671772.

7. Luo P, Zhao Y, Zhang B, Liu J, Yang $Y$ and Liu J. Study on the adsorption of Neutral Red from aqueous solution onto halloysite nanotubes. Water research. 2010;44(5):14891497.

8. Meshko V, Markovska L, Mincheva $M$ and Rodrigues AE. Adsorption of basic dyes on granular acivated carbon and natural zeolite. Water research. 2001;35(14):3357-3366. 
9. Doğan $\mathrm{M}$ and Alkan $\mathrm{M}$. Adsorption kinetics of methyl violet onto perlite. Chemosphere. 2003; 50(4):517-528.

10. Mckay GBHS, Blair HS and Gardner JR. Adsorption of dyes on chitin. I. Equilibrium studies. Journal of applied polymer science.1982;27(8):3043-3057.

11. Kumar KV. Optimum sorption isotherm by linear and non-linear methods for malachite green onto lemon peel. Dyes and Pigments. 2007;74(3):595-597.

12. Chia CH, Razali NF, Sajab MS, Zakaria S, Huang NM and Lim HN. Methylene blue adsorption on graphene oxide. Sains Malaysiana. 2013;42(6):819-826.

13. Moussavi G, Hossaini Z and Pourakbar M. High -rate adsorption of acetaminophen from the contaminated water onto doubleoxidized graphene oxide. Chem Eng J. 2016;287:665-673.

14. Deng JH, Zhang XR, Zeng GM, Gong JL, Niu QY and Ling J. Simulaneous removal of Cde (11)and ionic dyes from aqueous solution using magnetic graphene oxide nano composite as an adsorbent. Chem Eng J. 2013;226:189-200.

15. Wijdan A and Zaid H. Synthesis and characterization of new Fe-complex and its nanoparticle oxide using the novel photolysis method. International journal of pharmaceutical and phytopharmacological research. 2018;8:57-61.

16. Mahdi Heidarizad and Sevinc Sengor S. Synthesis of graphene oxide /magnesium oxide nanocomposites with high -rate adsorption of methylene blue., Journal of Molecular Liguids. 2016;224:607- 617.

17. Tavakoli MM, Tayyebi A, Simchi A, Aashuri $\mathrm{H}$, Outokesh $\mathrm{M}$ and Fan $\mathrm{Z}$. Physicochemical properties of hybrid grapheme -lead sulfide quantum dots prepared by supercritical ethanol. J Nanopart Res. 2015;17(1):1-13.

18. Amir Fahdil Dawood AL-Niaimi, Ghalib I Atiya and Donia A Abdulateef. Thermodynamics and kinetic study of Eosin dye adsorption on $\mathrm{CuO}$ nanoparticles, International Journal of Research in Pharmacy and Chemistry. 2018;8(2):281-293.
19. Kumer A and Kumer J. On the synthesis and optical absorption studies of nano-size magnesium oxide. 2008;

20. Tayyebi A, Outokesh M, Moradi S and Doram A. Synthesis and characterization of ultrasound assisted ,grapheme oxide magnetite hybrid, and investigation of its adsorption properties for $\mathrm{Sr}(11)$ and $\mathrm{CO}(11)$ ions. Appl Surf Sci. 2015;353:350-362.

21. Tayyebi A, Tavakoli MM, Outokesh $M$, Shaflekhani $A$ and Simchi AA. Supercritical synthesis and characterization of grapheme-PbS quantum dots composite with enhanced photovoltaic properties Ind. Eng Chem Res. 2015;54(30):7382-7392.

22. Tang Y, Guo H, Xiao L, Yu S, Gao N and Wang $Y$. Synthesis of reduced grapheme oxide/magnetic composites and investigation of their adsorption performance of fluoro-quinolone antibiotics,Colloids Surf. A Physiochem. Eng Asp. 2013;424: 1-13.

23. Fan L, Luo C, Li X, Lu F, Qiu H and Sun $M$. Fabrication of novel magnetic chitosan grafted with grapheme oxide to enhance adsorption properties for methyl blue. J Hazard Mater. 2012;215216,272-279.

24. Becerril HA, Mao J, Liu Z, Stoltenberg RM, Bao Z and Chen Y. Evaluation of solution processed reduced grapheme oxide films as transparent conductors. ACS Nano. 2008;2(3): 463-470.

25. Ju Ran Lee and Hye Young Koo. Growth of magnesium oxide nanoparticles onto grapheme oxide nanosheets by sol-gel process, Carbon Letters. 2013;14(4):206-209.

26. Bykkam S, RaoK V, S Charkra $\mathrm{CH}$ and Thunugunta T. Synthesis and characterization of grapheme oxide and its antimicrobial activity against Kiebseilla and Staphylococus, International Journal of advanced Biotechnology and research. 2013;|4(1):142-146.

27. G.Moussavi and Mahmoudi M. Degradation and biodegradability improvement of the reactive red 198 azo dye using catalytic ozonation with $\mathrm{MgO}$ Nanocrystals. Chem Eng J. 2009;152(1):1-7. 
28. Liu M, Dong F, Kang W, Sun S, Wei $\mathrm{H}$, Zhang $\mathrm{W}$ and Liu $\mathrm{Y}$. Biosorption of strontium from simulated nuclear wastewater by Scenedesmus spinosus under culture conditions: adsorption and bioaccumulation processes and models. International journal of environmental research and public health. 2014;11(6): 60996118.

29. Smaranda C, Gavrilescu M and Bulgariu D. Studies on sorption of Congo red from aqueous solution onto soil. International Journal of Environmental Research. 2011;5(1):177-188.

30. Amir F, Dawood Abd A, Khudheir A and Marwa I and Mubarak. Study Eosin Dye Adsorption on the Surface Waste of Molasses Dates Production. Diyala Journal for pure sciences.2017;13(1):22-41.

31. Lagergren S. About the theory of socalled adsorption of soluble substance. Kungliga Svenska.Vetenskapsakademiens. Ha ndlingar. 1898;21:1-39.

32. Chia CH, Razali NF, Sajab MS, Zakaria S, Huang, NM and Lim H.N. Methylene blue adsorption on graphene oxide. Sains Malaysiana. 2013;42(6):819-826 .

33. Karim $H$, Hassan and Eman $R$. Preparation and Characterization of Copper Oxide Nanoparticles Used to Remove Nickel lons from Aqueous Solution. Diyala Journal for pure sciences. 2017;13(2): 217-234.

34. Appel J. Freundlich, adsorption isotherm, surface Science. 1973;39:273-244.
35. Crosby DG. Environmental Toxicology and Chemistry. Oxford University Press, Oxford.1998;46.

36. Gan S, Zakaria $\mathrm{S}$, Chia $\mathrm{CH}$, Chen RS and Jeyalaldeen N. Physicomechanical properties of a microwave-irradiated kenaf carbamate/graphene oxide membrane. Cellulose. 2015;22(6): 3851-3863.

37. Fungaro DA, Yamaura $M$ and Carvalho TEM. Adsorption of anionic dyes from aqueous solution on zeolite from fly ash-iron oxide magnetic nanocomposite. Journal of Atomic and Molecular Sciences. 2011;2:305-316.

38. Stoeckli F. Recent developments in Dubinins theory. Carbon. 1998;|36(4):363-368.

39. Mall ID, Srivastava VC and Agarwal NK. Removal of Orange-G and Methyl Violet dyes by adsorption onto bagasse fly ash-kinetic study and equilibrium isotherm analyses. Dyes and pigments. 2006;69(3):210223.

40. Farghali $A A$, Bahgat $M$, Allah $A E$ and Khedr $\mathrm{MH}$. Adsorption of $\mathrm{Pb}$ (II) ions from aqueous solutions using copper oxide nanostructures. BeniSuef University Journal of Basic and Applied Sciences. 2013;2(2):61-71.

41. Haciyakupoglu S, Orucoglu E, Esen AN, Yusan S and Erenturk S. Kinetic modeling of selenium (IV) adsorption for remediation of contaminated aquatic systems based on mesoscale experiments. Desalination and Water Treatment. 2015;56(5):12081216. 